\title{
TRIGGERS OF SYMPTOMS AND HEALTH CARE*
}

\author{
LOIS M. VERBRUGGE \\ Institute of Gerontology, University of Michigan, 300 North Ingalls, Ann Arbor, MI 48109, U.S.A.
}

\begin{abstract}
This article studies triggers of physical symptoms and health care on a daily basis. The data used are health diaries kept for 6 weeks by 589 adults in metropolitan Detroit. The results show that bad moods consistently trigger physical problems and health actions (medical drug use, medical care, lay consultation, restricted activity) for men and women of all ages. Negative events have small effects on these outcomes, sometimes acting as triggers, but sometimes as dampers. Physical malaise (feeling bad overall) is an especially strong trigger for symptomatic people to take health actions. Iroubles of all kinds - - bad moods, physical malaise, symptoms, negative events - tend to repeat from one day to the next. Yesterday's troubles help trigger symptoms and health care today, but they have less influence than today's troubles do. When troubles continue for 2 days in a row, this spurs people especially to seek professional help. Women tend to respond more predictably and simply to triggers than men do, and older people appear to be more sensitive and responsive to triggers. The results indicate that the social stress and health model, which typically considers the longrun of major life events and chronic mental and physical conditions, is also apt for the shortrun of daily negative events, bad moods and physical discomfort and symptoms.
\end{abstract}

\section{INTRODUCTION}

In the past two decades, a theory of social stress and its consequences for health has been developed in the social sciences. It posits that stressful events can lead to physical. and mental problems. These problems are themselves reciprocally related, in other words, they can induce each other. When people have strong social support or sturdy coping abilities, the links between events, mental distress and physical symptoms are diminished, or buffered. Finally, mental and physical problems spur actions such as medical care and selfcare, an issue being which actions people choose from the many options. These hypotheses are typically tested in a time-frame of months or years. The items studied are major life events and chronic mental and physical conditions.

This article brings the social stress and health theory to a daily level. It asks how negative events, bad moods, general physical malaise, physical symptoms and health actions of a day are related to each other. We hypothesize that bad moods or negative events on a day increase the likelihood of physical symptoms the same day, and that bad moods have a stronger impact than negative events do (Hypothesis 1 ). We expect that bad moods, negative events and general physical malaise increase the likelihood that symptomatic people will take curative actions such as medical drugs, medical care, lay consultation and restricted activity (Hypothesis 2). Relationships across days are also

\footnotetext{
*An earlier version of this article was presented at the American Sociological Association meetings, Detroit, August 1983 with Yossi Harel. The author thanks $\mathrm{Mr}$ Harel for assistance in all aspects of the analysis and the reviewers for their suggestions. The research was supported by Research Grants from the Center for Epidemiologic Studies, National Institute of Mental Health (MH29478) and the National Science Foundation (SES-8218867). The author is Associate Research Scientist (Institute of Gerontology) and Faculty Associate (Institute for Social Research) at The University of Michigan.
}

studied. We hypothesize that troubles yesterday increase the chances of having symptoms and taking health actions today (Hypothesis 3); e.g. a bad mood yesterday increases the probability of symptoms today. Finally, if multiple troubles occur on a day (e.g. both a bad mood and a negative event) or if troubles persist for two days (e.g. a bad mood both days), the chances of symptoms and health actions rise markedly (Hypothesis 4).

Because the time-frame is short - just 1 or 2 days we call the predictors 'triggers' of symptoms and health care. The word 'triggers' was coined in the $1950 \mathrm{~s}$ by Zola [1]. Although felicitous, the term has rarely been used in subsequent empirical research.

\section{THE SOCIAL STRESS AND HEALTH MODEL}

The social stress and health model has generated research in the fields of medical sociology, social and psychiatric epidemiology, bchavioral medicinc and health psychology. The causal sequence usually posited is that certain life events cause great mental distress, which in turn lowers a person's physiological resistance to illness, so that both chronic and acute health problems increase. The impact of mental distress on illness can be direct (when it causes biochemical changes in the body) or indirect (when distressed people try to cope but choose behaviors, such as smoking, that harm the body) [2]. Research has concentrated on how stressful life events are related to mental distress, with much less attention to physical illness outcomes. Positive associations between events and distress are consistently found, though they are not always large ones [3-6]. This has spurred the search for modifying effects, factors that blunt or intensify the impact of events on mental distress. The search has concentrated on social support as a buffer. The notion is that people with stable social ties are more resilient, so they react to stress less profoundly than other people. Although research often finds a main effect for social support (i.e. people with extensive social ties are healthier), the evidence for buffering effects is weak [7]. 
Current research on the model is diversifying in several directions. First, interest in physical health outcomes and in coping behaviors is growing. Actually, early research on stress and health did focus on physical symptoms [8], so this constitutes a renewal of that attention. Researchers are also studying how people cope with experienced mental and physical symptoms, namely, how they seek professional help or opt for self-care. Second, the effects of specific life events and of prolonged stress are being studied [9-12]. Third, work on buffers has expanded to include psychological characteristics of individuals $[7,13-14]$ as well as their social supports. Fourth, time-frames are both lengthening to stretch across years and also shortening to daily phenomena. On the long side, it is thought that stressful events may have consequences for many years after they occur, and that a lifetime of supportive social tics may offer some resistance to degenerative disease and early death [15]. On the short side, stresses on a given day may affect a person's mood, sense of physical wellbeing, medication use, and professional helpseeking. Lazarus and his colleagues have made compelling appeals for better understanding of day-today experiences $[16,17]$. Finally, researchers are obtaining prospective data to reveal exact time sequences of events, mental states, physical states and coping behaviors. Such data are necessary to confirm causal relationships, and they have the added advantage of reducing recall error compared to retrospective data [18].

This article reflects the new emphases as follows: our dependent variables are physical symptoms and the curative actions people take for them. We study how negative events (but not more specific kinds) on a day affect these outcomes. The time-frame is one day or two consecutive days. The data come from prospective health diaries kept for 6 weeks by a population sample of adults. We do not study psychosocial buffers in this article. Recognizing that the links between events, mental distress, physical symptoms and health actions may differ for age groups and for gender, we do the analyses scparately for age-sex groups.

\section{RESEARCII ON DAILY TRIGGERS}

Until recently health diary studies were rare, so information about triggers of daily physical symptoms and health actions has been scant. Four studies provide these results: First, 512 women in Rochester, NY filled out daily health calendars for one month. Each day they noted any upsetting events for family members, rated their own tension level, rated the general health status of each family member, and listed symptoms, preventive actions and curative actions of family members [19]. Analyses showed that family stress increased the chances of symptoms among the women. Strangely, stress increased medical care for them on healthy days, but not on days with illness. The longer an illness lasted, the more likely women were to seek medical care for it $[20,21]$. Second, in a study of 55 university students and staff, respondents recorded daily 'life changes' and physical symptoms for a 2-9 week period [22]. The higher the daily life change score, the more likely physical symptoms were. Life changes were also more frequent on the day before and the day after symptomatic days, compared to nonsymptomatic ones. People with high average life change scores (over the whole diary period) had the least variable scores too; in other words, they tended to be persistently upset. Third, a study of 96 Boston women showed that after controlling for the presence of symptoms on a day, upsetting events boosted health services use [23]. Fourth, daily records for 23 men showed that nonsymptomatic days were preceded by more 'desirable' events than symptomatic days were [24].

Interest in triggers of physical symptoms has burgeoned, and several studies are in progress or recently completed. Two of the studies focus on daily stresses and emotional outomes, but they also include some information on physical symptoms (the investigators are R. Lazarus, University of California, Bcrkcley, and A. Stonc, State University of Ncw York, Stony Brook). Readers may also be interested in research results about triggers of daily mood [25], links among events, mood, physical symptoms, and actions based on aggregated rates from daily records $[23,25-27,29-32]$, and similar links based on shortterm retrospective questions in panel studies [33-35].

\section{DATA SOURCE}

The Health In Detroit Study is a survey of white adults $(18+$ years old $)$ residing in the Detroit metropolitan area in Fall 1978. A multistage probability sample of households was selected; in each, one adult was selected as the study respondent. An initial interview was conducted at home covering such topics as current health status, chronic conditions, health actions in the past year, health attitudes, and social roles. Respondents then kept Daily Health Records for 6 weeks. Each day they answered questions about their general physical wellbeing, symptoms of illness or injury, curative and preventive actions, mood and special events. At the end of the diary period, a termination interview was conducted by telephone with questions about changes in health during the 6 weeks and reactions to the diary task. Details of the study design are in $[18,36]$. There are 714 interviewed respondents $(302$ men and 413 women) and 589 diary respondents (243 men and 346 women who kept at least one week of Daily Health Records). The 589 diary-keepers produced 23,526 days of information.

\section{VARIABLES}

The predictors, dependent variables, and control variables used for this article are described below. All variables except age and sex are daily ones and come from the Daily Health Record (shown in Appendix 1). All were dichotomized for the analysis, so that 1 is the occurrence of an event, mood, symptom or health action, and 0 otherwise.

\section{Predictors}

Negative

Event "Did anything happen - for better
or worse - to make today different
than usual?".
If yes, people indicated the kind of
event (there were 8 check-boxes; see 
Appendix 1). Events were coded by their desirability, using the PERI Events are Trouble with family or friends and A lot of extra work. For this analysis, $1=$ Negative Event and $0=$ Positive, Ambiguous or No Event.

Bad Mood "How were your spirits today?" Scored from $1=$ terrible to $10=$ wonderful. Dichotomized here into $1=$ Bad Mood (scores 1-5) and $0=$ Good Mood (scores 6-10) $\uparrow$.

Physical "How did you feel physically Malaise (or Bad Physical Feelings) today?"

Scored from $1=$ terrible to $10=$ wonderful. Dichotomized here into $\mathbf{1}=$ Bad Physical Feelings

Dependent variables scale $[37]^{*}$. The main Negative

Symptomatic Day

Medical Drug Day* (scores 1-5) and $0=$ Good Physical Feelings (scores 6-10).

Note: in this article Physical Malaise is usually treated as a predictor. The item was worded to elicit general physical wellbeing, which is conceptually distinct from the experience of specific illness and injury symptoms. To see if overall malaise has a special triggering effect (apart from symptoms) on health actions, we give it predictor status.
*The PERI scale is for major life events; nevertheless it is an adequate guide for scoring daily events into Negative, Positive and Ambiguous categories.

$\dagger$ The frequency distributions for mood and physical feelings are skewed towards the positive side. For this analysis we defined good and bad states according to the original scores $(6-10$ vs $1-5)$. The entire analysis was also performed using standardized, or ipsative, scores. For this, each individual's average for all diary days was computed; then each day's deviation from that average was computed and represented in standard deviations from the average. The scores were thus deviations from the usual for each person; relatively good states were positive $(+)$ scores and relatively bad states were negative (-) scores. Results are virtually the same for both the original and standardized scores, but they tend to be slightly moderated for the latter. A possible explanation is that the associations using original scale items contain the impact of personal characteristics (across individual) as well as personal variation (intraindividual), while those using standardized scale items contain only the intra-individual variations. To the extent sociodemographic groups vary in the triggering processes, the original scale results will be sharper.

†Alternative terms are 'medication' instead of 'medical drug', and 'therapeutic medication' instead of 'curative drug'. The terms we have chosen are sufficiently clear and acceptable in medical sociology parlance, though clinician readers might prefer the others.

$\S$ All respondents, symptomatic or not, were asked about preventive medical care on the day too ("Did you visit or telephone a clinic, doctor or dentist's office, or hospital today for any reason besides symptoms you might have had today?"). Since our focus is curative behaviors, the item is not analyzed here.

\section{Curative \\ Drug Day}

Medical

Care Day

Lay

Consultation

Day

Restricted

Activity

Day

\section{Controls \\ Age-Sex \\ Groups}

"Did you have any symptoms or discomforts today?"

Respondents were asked to answer Yes for any symptoms of physical illness or injury. If Yes, they filled in a chart with details about the symptoms. $1=$ Yes, $0=$ No.

"Did you take any pills, medicines, or treatments for your health today - to treat a symptom, prevent illness, or to become more healthy in general?"

If Yes, respondents filled in a chart with details about the drugs. $1=$ Yes, $0=$ No.

A day where the Drug Chart shows that a drug was taken to cure a symptom experienced that day.

The variable is therefore for Symptomatic Days only. Respondents checked a box in the Chart indicating the curative purpose ("To treat symptoms bothering you today"). $1=$ Yes, $0=$ No.

"Did you seek medical or dental help about today's symptoms?"

This was asked for Symptomatic Days only§. It includes making an appointment, phone conversations with doctor/dentist for advice, visits to clinic/office/emergency room, and hospital admission. Dental appointments and contacts were a small fraction of the total. $1=$ Yes. $0=$ No.

"Did you talk with anyone else [besides a physician] today - such as relatives, neighbors, friends about your symptoms?"'

This was asked for Symptomatic Days only. If Yes, respondents checked the kind of person consulted (Your husband/wife; Other members of your household; etc., see Appendix 1). For this analysis, we study whether lay consultation occurred or not, but do not consider the kind of person. $1=$ Yes, $0=$ No. "Because of today's symptoms, did you cut down on the things you usually do?"

This was asked for Symptomatic Days only. If Yes, respondents checked the kind of restrictions (Stayed in bed: Cut down on household chores or errands; etc., see Appendix 1). For this analysis, we study whether restricted activity occurred or not, but do not consider the kind of restriction. $1=$ Yes, $0=$ No.

Six age-sex groups are studied: men ages $18-34,35-54,55+$ and women 
Type of Symptom

\section{in those age ranges}

The two most common types of symptoms are Respiratory $(35 \%$ of All Symptomatic Days) and Musculoskeletal $(35 \%)$. The analyses of curative health actions were done for All Symptomatic Days and for the two subgroups as well. The results for Respiratory Days and Musculoskeletal Days are so similar to the total, we have chosen to discuss only All Symptomatic Days. Some results for Respiratory and Musculoskeletal symptoms are in Table 1 and several of the Figures.

\section{METHODS}

Within-day relationships are studied first: the zeroorder associations among events, moods, malaise and symptoms are reported. Then we consider the relative frequency of each health action given the occurrence of a bad vs good mood, a negative event vs no negative event and bad vs good physical feelings. We then look at two predictors together and ask if there are contingent, or interaction, effects. For example, do negative events have the same impact on bad mood days as on good mood days? We also ask if multiple troubles on a day greatly increase the chances of symptoms and curative actions. All of these questions involve conditional probabilities, which are readily produced from crosstabulations of the variables. For the within-day relationships, the unit of analysis is a diary day $(N=23,526)$.

Across-day relationships are studied to see if triggering effects carry over from one day to the next. We consider yesterday's effects on today, and not longer lags. Does a trouble (negative event, bad mood, physical malaise) yesterday influence symptoms and health actions today? Again, the question involves conditional probabilities (first with no control for today troubles, then with control for them) and the results are based on crosstabulations. For the acrossday relationships, the unit of analysis is pairs of days $(N=22,937)$.

Our hypotheses are stated causally - that negative events, bad moods and physical malaise trigger certain health outcomes. Causality cannot be determined with certainty for items measured the same day. Thus, if the within-day findings fit the hypotheses, this is only partial support for the causal statements and our interpretations must be suitably modest. By contrast, the results for across-day relationships have a clear time sequence, so they offer stronger support of causality and can be interpreted that way with more confidence.

Some diary-keepers quit the study before completing 6 weeks of Daily Health Records. Analyses of dropout rates show that young men (under 30 years) and older people $(65+$, especially women) were more likely to quit than other age-sex groups [38]. This selectivity poses no problem for our analyses within age-sex groups, but for those with the whole array of diary days, some groups are under-represented. Trial analyses which included weights to standardize the diary periods for all people showed that selectivity has minimal impact on the relationships among variables. We therefore use the nonweighted ('raw') sample of diary days here.

\section{RESULTS AND DISCUSSION}

The frequency of troubles for age-sex groups

Table 1 shows the daily frequency of negative events, bad moods, physical malaise, symptoms and health actions for the age-sex groups. Women experience bad moods and physical malaise more often than men do $(15.4 \%$ of women's days involve a bad mood compared to $10.4 \%$ of men's; malaise occurs on $15.4 \%$ of women's days and $10.3 \%$ of men's). For women, both troubles increase with age (to see this, scan the full distributions). For men, moods and physical feelings are also worst at older ages, but they tend to be best in middle age. Women also report more negative events $(15.9 \%$ of their diary days) than men do $(11.1 \%)$. The experience of negative events does not vary much across age for either sex.

Symptomatic days are much more common for women than for men $(42.0 \%, 31.3 \%)$. Medical drug use on any day (symptomatic or not) is substantially greater for women $(61.4 \%$ vs $43.6 \%)$ [39]. But on symptomatic days, women are only a little more likely to use drugs to relieve the problem $(60.4 \%$ vs $54.0 \%)$. And sex differences for the other curative actions are small. This means that symptomatic men and women are quite similar in their propensity to get medical care, consult with family and friends, and restrict activities. (Note that the statement is for symptomatic days. If the rates were based on all diary days, women would have higher health action rates, simply because they have more symptomatic days than men do.) With increasing age, the propensity to take curative actions for one's symptoms increases. Lay consultation is an exception, showing no pattern across age.

Basic links among negative events, bad moods, physical malaise and physical symptoms

All the associations are positive (measured by gammas, $\gamma$ ). Bad moods are strongly linked to physical malaise $(0.96)$ and moderately to physical symptoms (0.69). To a smaller extent, negative events tend to occur on the same days as symptoms $(0.40)$ and malaise $(0.33)$. Negative events are even more strongly linked to bad moods $(0.56)$ on a day. These zero-order associations suggest that negative events help trigger bad moods, but they have a rather distant effect on symptoms and malaise. By contrast, bad moods are a proximal and direct trigger for physical troubles. This is rudimentary support for the causal chain of the social stress and health model: negative events spur mental distress, which in turn leads to physical problems. We shall find more support for this sequence in other results.

We are not surprised to find the link between bad moods and physical malaise stronger $(0.96)$ than the link between malaise and symptoms (0.83). The mood and malaise items are both subjective and general, whereas the symptom item is more objective and specific. We believe the tight association reflects close causal ties between mood and malaise on a daily basis. not (as some might argue) people's inability to distinguish their emotional and physical wellbeing. 
Table 1. Diary variables for age-sex groups

\begin{tabular}{|c|c|c|c|c|c|c|c|c|c|}
\hline & \multirow[b]{2}{*}{ Total } & \multicolumn{4}{|c|}{ Men } & \multicolumn{4}{|c|}{ Women } \\
\hline & & $\begin{array}{l}\text { All ages } \\
\text { (Nur }\end{array}$ & $\begin{array}{c}18-34 \\
\text { ber of dia }\end{array}$ & $\begin{array}{c}35-54 \\
\text { days and }\end{array}$ & $\begin{array}{c}55+ \\
\text { rcents) }\end{array}$ & All ages & $18-34$ & $35-54$ & $55+$ \\
\hline \multicolumn{10}{|l|}{ All days } \\
\hline No. of diary days & 23526 & 9680 & 4056 & 3420 & 2204 & 13846 & 5719 & 4668 & 3459 \\
\hline \multicolumn{10}{|l|}{ Mood } \\
\hline 1 Terrible & 0.6 & 0.6 & 0.5 & 0.2 & 1.3 & 0.7 & 1.0 & 0.5 & 0.5 \\
\hline 2 & 0.9 & 0.8 & 1.4 & 0.4 & 0.4 & 0.9 & 1.0 & 0.8 & 0.9 \\
\hline 3 & 1.8 & 1.1 & 1.6 & 0.7 & 0.8 & 2.3 & 2.3 & 2.3 & 2.3 \\
\hline 4 & 2.5 & 1.9 & 2.2 & 1.7 & 1.7 & 3.0 & 2.8 & 3.5 & 2.6 \\
\hline 5 & 7.5 & 6.0 & 5.6 & 5.4 & 7.7 & 8.5 & 7.5 & 9.1 & 9.5 \\
\hline - & - & - & - & - & - & - & - & - & - \\
\hline 6 & 11.3 & 9.8 & 7.9 & 11.9 & 10.0 & 12.4 & 10.8 & 12.9 & 14.6 \\
\hline 7 & 14.1 & 14.3 & 13.7 & 16.0 & 12.8 & 13.9 & 15.6 & 13.6 & 11.6 \\
\hline 8 & 25.1 & 27.4 & 28.7 & 26.2 & 26.7 & 23.5 & 22.9 & 23.0 & 24.8 \\
\hline 9 & 22.0 & 24.4 & 25.3 & 23.1 & 24.8 & 20.3 & 21.0 & 20.1 & 19.4 \\
\hline \multirow[t]{2}{*}{10 Wonderful } & 14.2 & 13.7 & 13.1 & 14.4 & 13.8 & 14.5 & 15.1 & 14.2 & 13.8 \\
\hline & $100.0 \%$ & & & & & & & & \\
\hline \multicolumn{10}{|l|}{ Physical feelings } \\
\hline 1 Terrible & 0.6 & 0.6 & 0.4 & 0.1 & 1.4 & 0.6 & 0.9 & 0.3 & 0.6 \\
\hline 2 & 0.6 & 0.4 & 0.5 & 0.3 & 0.4 & 0.8 & 1.0 & 0.5 & 0.8 \\
\hline 3 & 1.4 & 0.8 & 1.0 & 0.6 & 0.8 & 1.8 & 1.6 & 1.8 & 2.1 \\
\hline 4 & 2.8 & 1.9 & 1.9 & 1.6 & 2.1 & 3.4 & 2.6 & 4.7 & 2.9 \\
\hline 5 & 7.9 & 6.6 & 6.9 & 5.2 & 8.1 & 8.8 & 6.4 & 8.4 & 13.5 \\
\hline - & - & - & - & - & - & $\ldots$ & - & - & $\underline{-}$ \\
\hline 6 & 10.9 & 10.0 & 8.2 & 12.7 & 9.2 & 11.6 & 10.4 & 12.3 & 12.7 \\
\hline 7 & 14.0 & 14.1 & 12.5 & 16.4 & 13.2 & 14.0 & 16.5 & 14.0 & 9.7 \\
\hline 8 & 25.6 & 27.9 & 29.4 & 26.4 & 28.2 & 24,0 & 22.9 & 23.9 & 25.8 \\
\hline 9 & 23.1 & 25.1 & 25.9 & 23.7 & 26.0 & 21.6 & 22.7 & 20.7 & 21.0 \\
\hline \multirow[t]{2}{*}{10 Wonderful } & 13.1 & 12.6 & 13.3 & 13.0 & 10.6 & 13.4 & 15.0 & 13.4 & 10.9 \\
\hline & $100.0 \%$ & & & & & & & & \\
\hline Negative event $(\%)$ & 13.9 & 11.1 & 11.5 & 10.1 & 12.0 & 15.9 & 16.6 & 15.4 & 15.5 \\
\hline Symptomatic day $(\%)$ & 37.5 & 31.3 & 28.9 & 32.4 & 33.0 & 42.0 & 41.4 & 41.8 & 43.2 \\
\hline \multicolumn{10}{|l|}{ Medical drug day } \\
\hline (any purpose) $(\%)$ & 53.4 & 43.6 & 32.0 & 42.1 & 66.6 & 61.4 & 54.9 & 55.3 & 80.5 \\
\hline \multicolumn{10}{|l|}{ Symptomatic days } \\
\hline No. of symptomatic days & 8652 & 2951 & 1132 & 1097 & 772 & 5701 & 2312 & 1931 & 1458 \\
\hline Curative drug day $(\%)$ & 58.2 & 54.0 & 49.5 & 53.1 & 62.5 & 60.4 & 52.7 & 62.3 & 70.0 \\
\hline Medical care day $(\%)$ & 5.0 & 5.4 & 3.8 & 6.4 & 6.4 & 4.8 & 4.2 & 3.7 & 7.3 \\
\hline Lay consultation day $(\%)$ & 48.1 & 47.6 & 48.4 & 43.7 & 52.0 & 48.4 & 51.6 & 44.0 & 49.0 \\
\hline Restricted activity day (\%) & 23.7 & 23.5 & 21.4 & 22.9 & 27.7 & 23.8 & 20.6 & 21.0 & 32.6 \\
\hline \multicolumn{10}{|l|}{ Respiratory symptom days } \\
\hline \multicolumn{10}{|l|}{ No. of respiratory } \\
\hline symptom days & 3070 & 949 & 433 & 376 & 140 & 2121 & 967 & 772 & 382 \\
\hline Curative drug day $(\%)$ & 68.7 & 63.4 & 63.5 & 64.1 & 61.4 & 71.1 & 62.6 & 72.5 & 89.5 \\
\hline Medical care day $(\%)$ & 4.3 & 3.2 & 2.6 & 3.7 & 3.6 & 4.8 & 4.7 & 3.5 & 7.4 \\
\hline Lay consultation day $(\%)$ & 48.3 & 48.5 & 52,4 & 46.7 & 41.0 & 48.3 & 51.4 & 47.4 & 42.4 \\
\hline Restricted activity day (\%) & 22.5 & 19.7 & 21.8 & 16.5 & 21.6 & 23.8 & 20.8 & 21.6 & 36.1 \\
\hline \multicolumn{10}{|l|}{ Musculoskeletal symptom days } \\
\hline No. of musculoskeletal & & & & & & & & & \\
\hline symptom days & 3054 & 1097 & 355 & 362 & 380 & 1957 & 519 & 502 & 936 \\
\hline Curative drug day $(\%)$ & 56.3 & 46.8 & 33.8 & 39.8 & 65.5 & 61.7 & 47.8 & 56.0 & 72.4 \\
\hline Medical care day $(\%)$ & 6.3 & 7.5 & 4.8 & 9.1 & 8.5 & 5.6 & 4.9 & 3.2 & 7.4 \\
\hline Lay consultation day $(\%)$ & 48.3 & 48.6 & 47.6 & 40.3 & 56.8 & 48.3 & 56.1 & 45.4 & 45.6 \\
\hline Restricted activity day $(\%)$ & 29.4 & 28.4 & 15.8 & 32.6 & 36.2 & 30.0 & 29.3 & 23.7 & 37.8 \\
\hline
\end{tabular}

*For details about items, sec Variables section in text.

Our analysis will show consistent differences in how moods and malaise trigger health outcomes; this buttresses the notion that people perceive the difference between them.

Overall, the zero-order results tell us that bad moods, physical malaise, and physical symptoms form a close nexus in daily life.

How do negative events and bad moods trigger physical troubles?

Figures 1 and 2 show how combinations of bad moods and negative events help trigger physical symptoms and physical malaise. (In this section only, malaise is treated as a dependent variable, to probe how moods and events may affect it. Elsewhere, it is a predictor; see Note in Variables section.) Negative events have contingent effects: On bad mood days, they have no triggering impact on symptoms (Fig. 1). This nil effect comes mainly from middle-aged groups, and older people do show a moderate triggering effect (see Fig. 2). But on good mood days, a negative event markedly increases the chances of symptoms for all age-sex groups. Without exception, mood is the predominant trigger for symptoms. Negative events take a secondary and specific role; they tend to influence symptoms directly only when the more important trigger is absent. The most pronounced effects of bad moods and negative events on symptom 


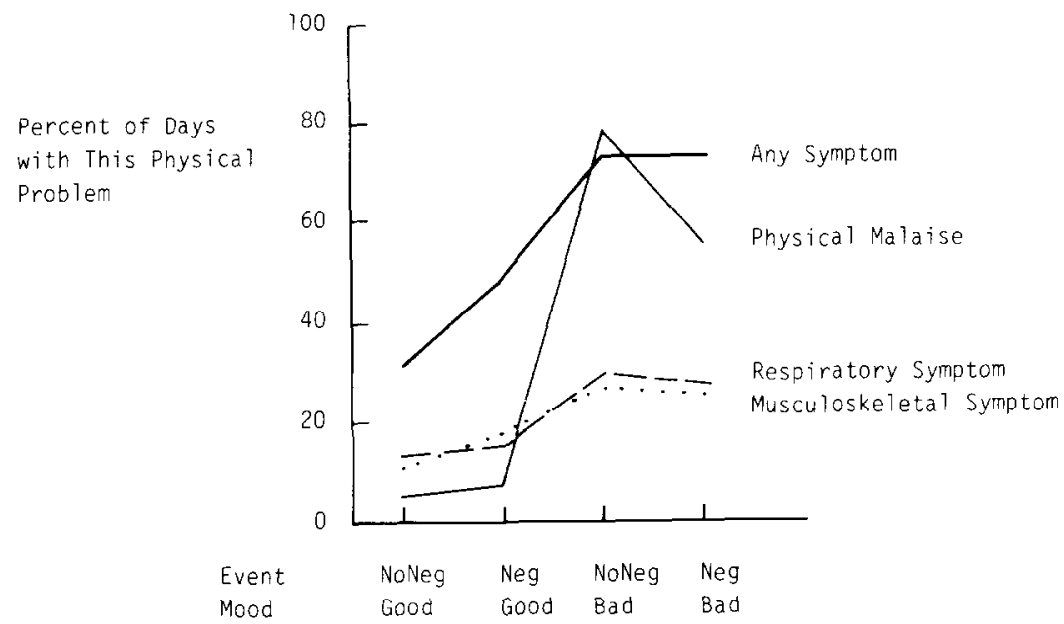

Fig. 1. Triggering effects of bad moods and negative events on physical symptoms and physical malaise. Key to all Figures: two predictors are used in each Figure. The lower one is hypothesized to have a stronger effect than the upper one. (In Fig. 1, these are bad moods and negative events, respectively.) We therefore expect a monotonic increase in the dependent variable from the left side to the right side, as the number and strength of triggers increase. A continuous line is drawn across the four combinations to assess this. To see the effect of the lower predictor, compare levels at the 1 st and 3rd points on the $X$-axis, and also the 2 nd and 4 th points. To see the effect of the upper predictor, compare levels at the 1 st and 2 nd points, and also the $3 \mathrm{rd}$ and 4 th points. The numerical data used for the Figures are available on request.

Percent

Symptomatic

Days
Percent

Physical

Malaise

Days

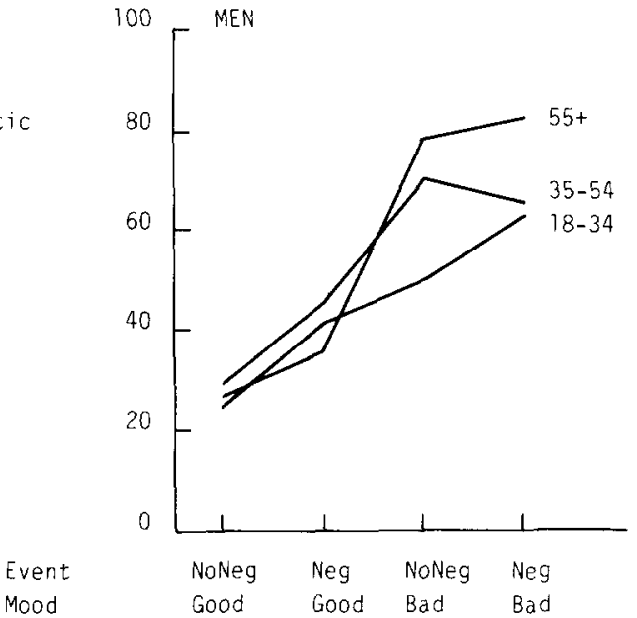

Mood
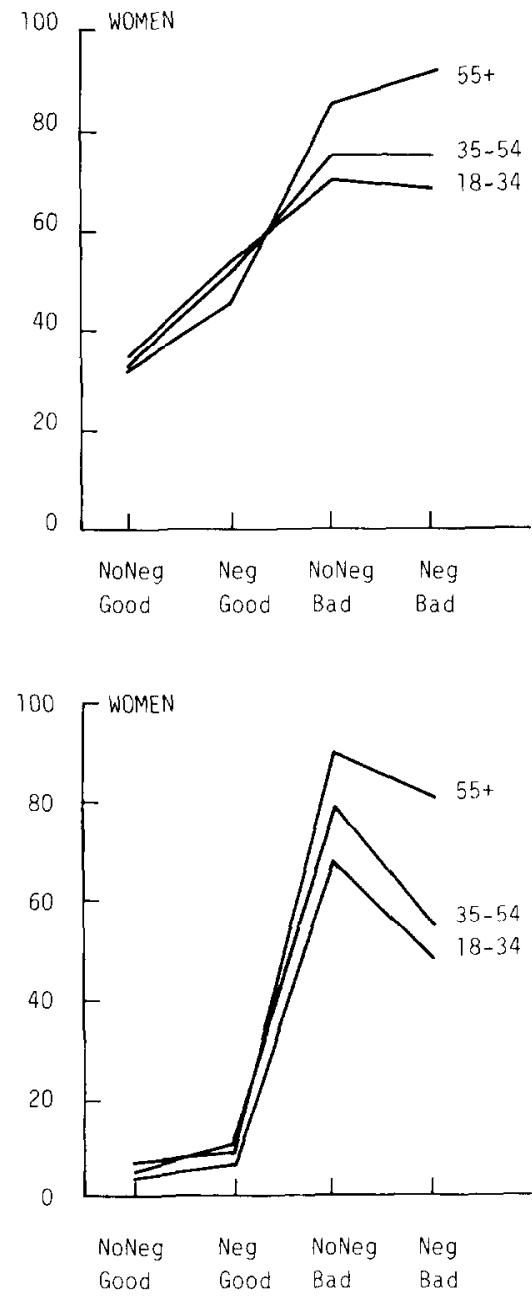

Event

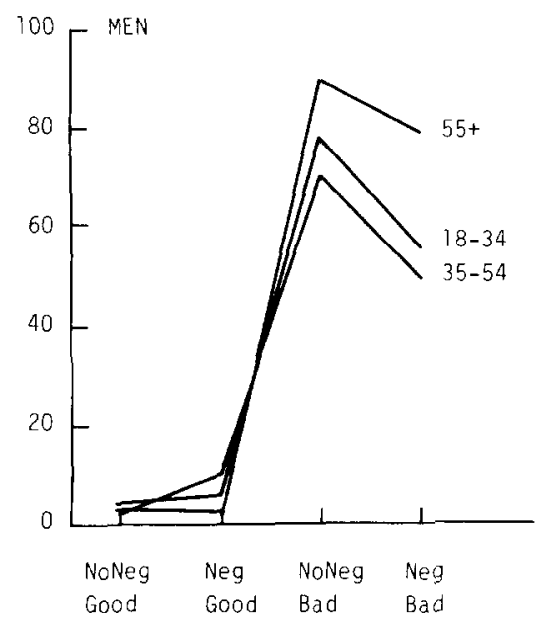

Good

Fig. 2. Triggers of physical symptoms and physical malaise, for age--sex groups. 
experience are among older people; in other words, they respond somatically to low spirits and disruptive events more than other age groups do.

The triggers for physical malaise are quite different (Fig. 1). On bad mood days, negative events actually reduce the likelihood of malaise. Do disruptive events sometimes draw people's attention away from emotional distress and break its pathway to somatic problems? On good mood days, most people feel so fine that a negative event does not dent that situation. These patterns appear for all age-sex groups (Fig. 2). Once again, the effect of bad moods on physical malaise is stronger for older people than at other ages. The effect of negative events (occurring only on bad mood days) is similar for all age-sex groups.

The differing patterns for symptoms and malaise demonstrate that these are different aspects of physical health-one measuring symptoms of illness and injury, the other 'feeling bad all over'. Although moods have a similar effect on them, negative events do not. Events are a trigger for symptoms on good mood days, but they are a kind of buffer for malaise on bad mood days.

\section{Triggers of medical drug use}

How do moods, events, malaise and symptoms trigger medical drug use on any day? And on symptomatic days, how do moods, events and malaise trigger curative drug use?

Medical drug use on any day. Symptoms are understandably the strongest prod for drug use $(78.1 \%$ of symptomatic days involve drug use, vs $39.6 \%$ of nonsymptomatic days). But all other troubles spur it too: Medical drugs are used on $77.6 \%$ of bad physical feeling days vs $50.1 \%$ of good physical feeling days. Moods rank next, with drugs used on $71.7 \%$ of bad mood days compared to $51.2 \%$ of good mood days. Negative events rank last $(61.8 \%$ on negative event days vs $52.8 \%$ on other days). Note how the ordering of importance fits the causal chain of the social stress and health model (physical problems the closest determinant of actions, then moods intermediate, and negative events the farthest back).

When are bad moods especially likely to trigger drug use? Controlling for the pressure of physical discomforts, we examine the additional effect of mood (Fig. 3, top and middle panels). Bad moods consistently boost drug use for women (with one exception in the Figure). The effect of bad moods for them is strongest when no physical problems are present. Moods have less consistent effects on men's medical drug use, sometimes boosting it, sometimes not.

When are negative events a special trigger? Controlling for mood, we examine the additional effect of events (Fig. 3, bottom panel). In general, negative events have a small boosting impact on good mood days, but nil or a slightly diminishing effect on bad mood days.

Again we see evidence that when a proximal trigger is absent, a more distant one is free to operate. Bad moods operate most in the absence of physical discomforts, and negative events operate most in the absence of bad moods. The proximal trigger may preoccupy people so much that others are unimportant.
But occasionally, a distant trigger can draw people's attention from their distress. Once again we see how negative events can sometimes reduce the likelihood of an outcome (hcre, drug usc) on days with bad moods.

The results for both moods and negative events are more consistent for women than for men. This means that women of all ages respond more uniformly, or predictably, to stressors than men do in seeking drug relief.

Curative drug use on symptomatic days. Curative drug use occurs in the presence of symptoms. They are already one trouble in the day; additional troubles increase the likelihood of curative drug use even more: They are used on $70.1 \%$ of bad physical feeling days vs $53.3 \%$ of good physical feeling days, and on $67.7 \%$ of bad mood days vs $55.0 \%$ of good mood days. Negative events actually decrease curative drug use a bit $(55.7 \%$ of negative event days vs $58.9 \%$ of other days). Note how importance fades as we move back from physical discomforts to mood, and then to negative events.

Figure 4 shows when bad moods and negative events operate most strongly. Bad moods are important only when physical feelings are also bad; this is one of the first times we see a distant factor acting in concord with a proximal one. This effect is strongest for older women and middle-aged men. Negative events reduce curative drug use regardless of mood; thus, drug use is actually less likely on negative event days than other days. We have seen this counterintuitive effect before. The pattern appears for most age-sex groups. (Later, we will discuss summary profiles for age-sex groups. The data for the groups are in Figs 8 and 9.)

\section{Triggers of medical care on symptomatic days}

Figure 5 shows how moods, events and malaise trigger medical care for symptoms. Medical care is boosted twofold or more if bad moods, negative events or bad physical feelings are also present on a symptomatic day. Malaise has the largest impact; $9.4 \%$ of symptomatic days have medical care when people feel bad overall vs $3.3 \%$ of days without malaise. Bad moods rank next, increasing medical care to $8.9 \%$ of symptomatic days vs $3.7 \%$ for good moods. Negative events are last $(8.1 \%$ vs $4.2 \%$ for days with no negative event).

Moods and events consistently trigger curative medical care by men of all ages. The combination of a bad mood with malaise is especially likely to spur middle-aged and older men to seek care. For women, the mood and event effects are more modest (the sole notable one being for older women, who increase their medical care greatly when a negative event occurs). But malaise spurs symptomatic women to seek medical care much more than it does men. This is an intriguing sex difference; general physical discomfort is the extra prod for women to seek care, whereas nonphysical factors are the extra prod for men.

\section{Triggers of lay consultation on symptomatic days}

People often seek consolation and advice about their symptoms from family members and friends. They talk with the hope of getting some relief from their symptoms; we therefore consider lay consultation a curative action. The chances of lay 

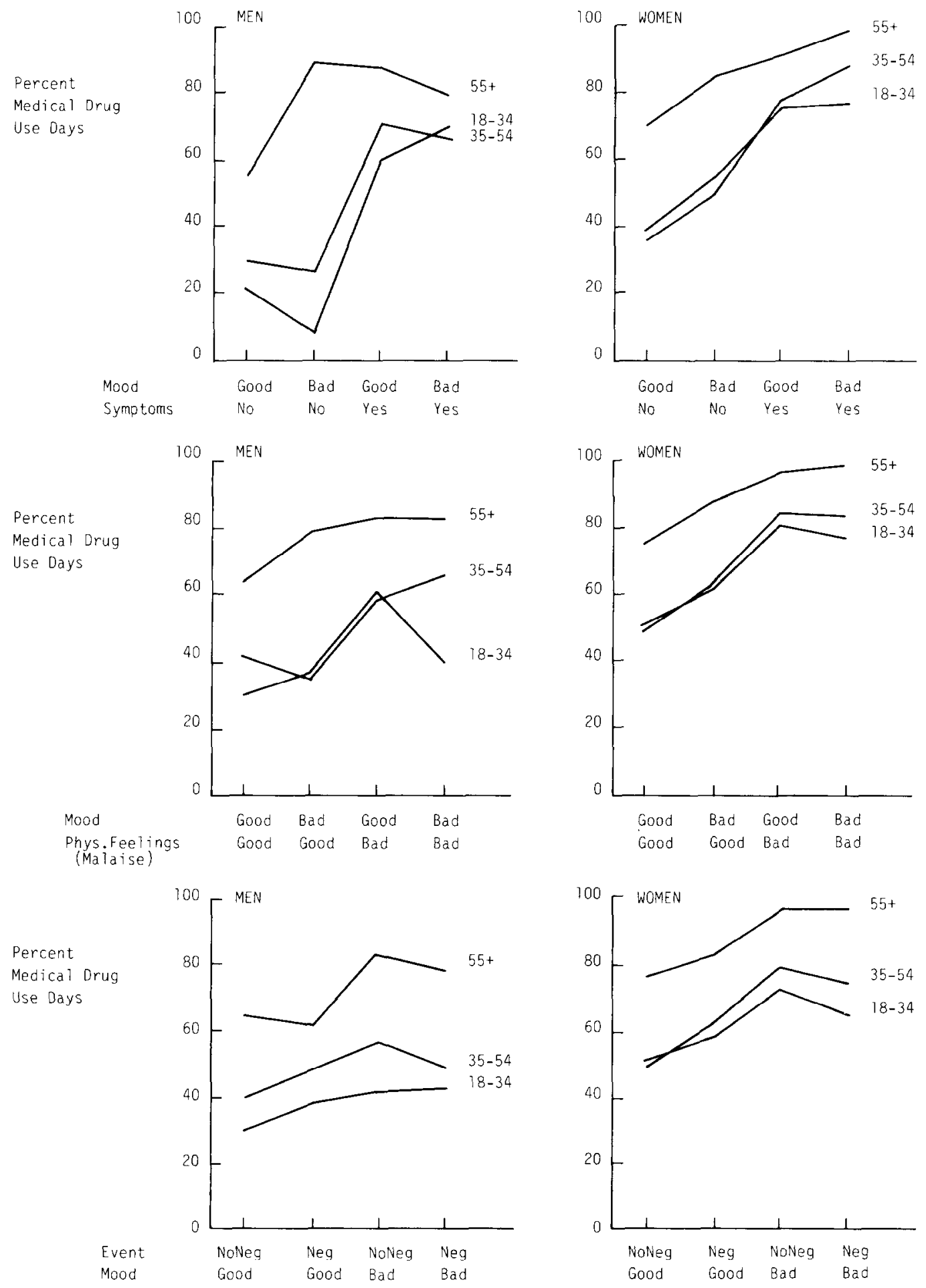

Fig. 3. Triggers of medical drug use, for age--sex groups. 


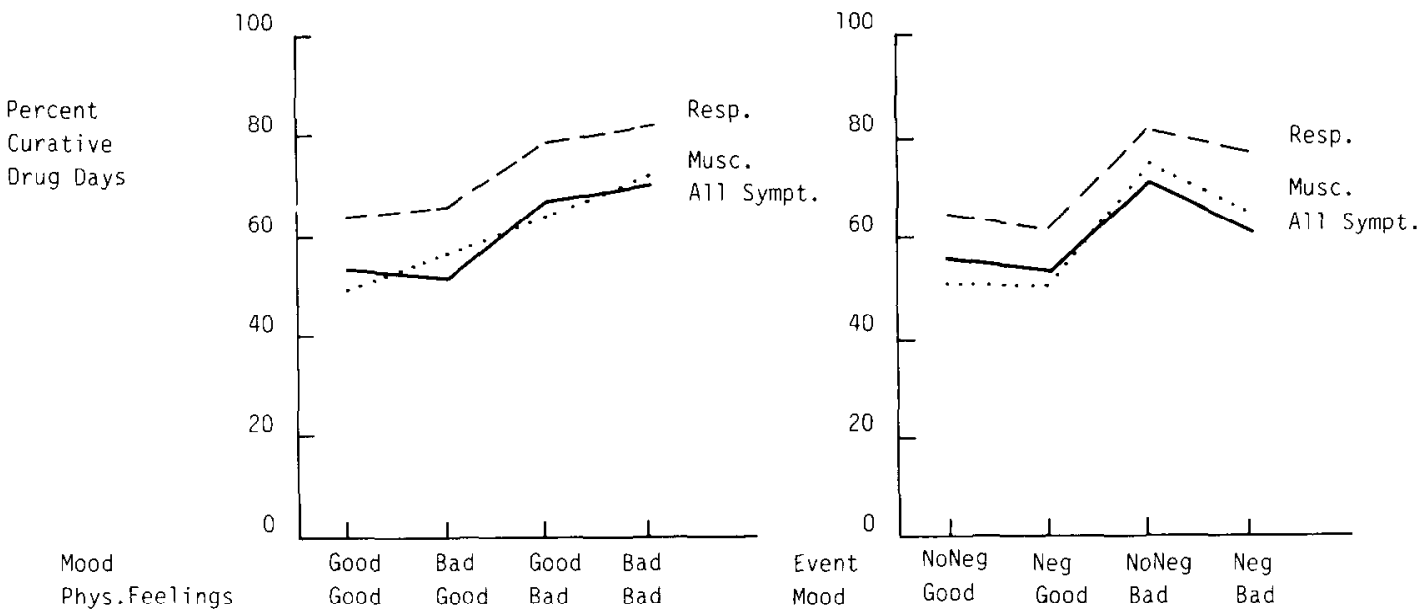

Fig. 4. Triggers of curative drug use on symptomatic days.

consultation are increased greatly by physical malaise $(62.4 \%$ vs $42.4 \%)$, substantially by bad moods $(59.1 \%$ vs $44.3 \%$ ), and a little by negative events $(54.6 \%$ vs $46.4 \%$ ). This ranking of triggers is now familiar to readers.

The boosting effect of bad moods occurs whether malaise is felt or not (Fig. 6). Bad moods trigger talking by symptomatic men more than by women. (In fact, dispirited women of some ages talk less with their family and friends than good-spirited ones do.) By contrast, symptomatic women are more affected by malaise than by bad moods. The greater importance of moods for men was noted earlier, and we will discuss it more in the Conclusion.

Negative events trigger conversation when moods are good; this appears for all age-sex groups. When moods are bad, events actually reduce conversation for most age groups (not visible in Fig. 6; see Fig. 8). Again we see contingent effects for events, either unmasked on good mood days or damping on bad mood days.

\section{Triggers of restricted activity on symptomatic days}

Symptomatic people tend to restrict their activities more if they also feel bad overall, have bad moods, or

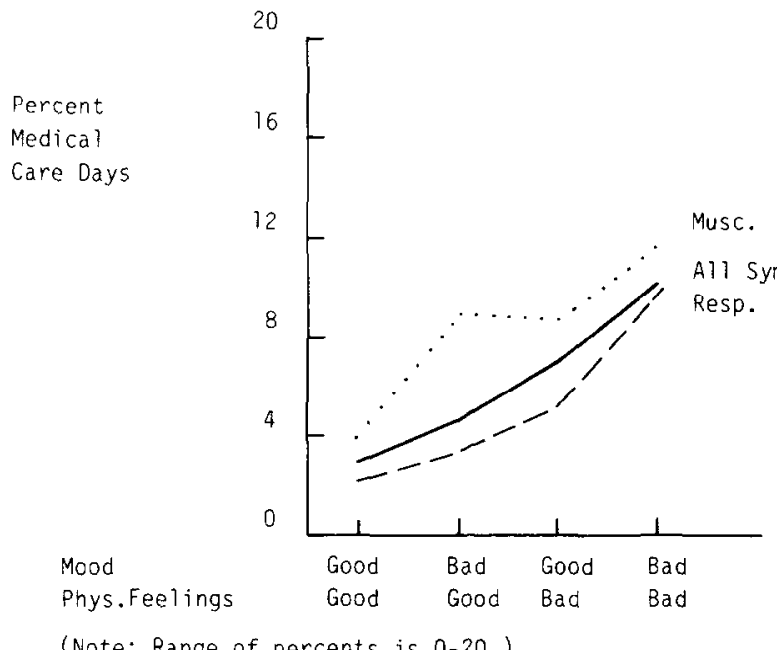

experience a negative event. Malaise ranks first, causing a three-fold increase $(46.6 \%$ of bad feeling days involve restricted activity vs $14.0 \%$ of good feeling days). Bad moods rank a close second $(45.7 \%$ of bad mood days have restricted activity vs $16.0 \%$ of good mood days). Negative events have a small boosting effect $(27.6 \%$ vs $22.7 \%$ of no negative event days). Restricted activity is an inexpensive and easy response to these added troubles, compared to seeking medical care. The data reflect this, with threefold or greater increases in restricted activity, compared to somewhat smaller increases in medical care.

Bad moods have their effect whether malaise is present or not (Fig. 7). This is true for most age-sex groups. But the intriguing sex difference reappears: Men are more responsive to bad moods than women are. By contrast, women are more responsive to malaise.

Negative events have a triggering effect only when moods are good; the event penetrates through the good mood to spur restricted activity. But on bad mood days, restricted activity is actually less likely when a negative event also occurs. These results appear for most age-sex groups.

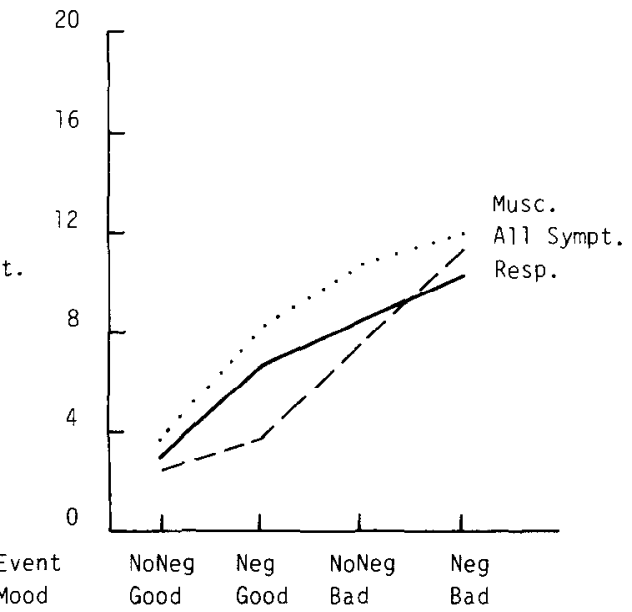

Fig. 5. Triggers of medical care on symptomatic days. 


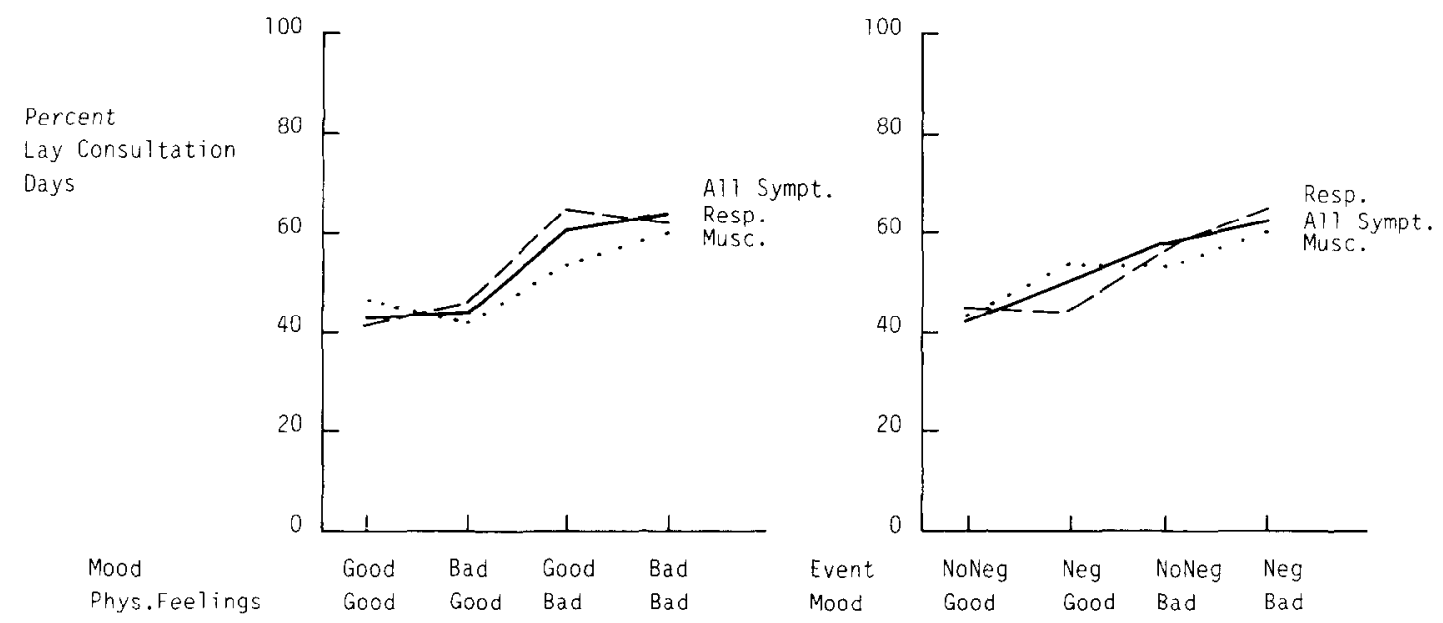

Fig. 6. Triggers of lay consultation on symptomatic days.

\section{Health action profiles for age-sex groups}

We have found that bad moods, bad physical feelings and (sometimes) negative events spur health actions among symptomatic people. Now we look at curative behaviors simultaneously and derive a profile for each age-sex group. Figure 8 shows the frequency of health actions for the six groups, by levels of mood and malaise.

Among young men, bad moods increase all types of actions; but they spur only restricted activity for women. Women's behavior is influenced mostly by physical feelings instead. Both sexes show similar preferences among the actions: Curative drugs and lay consultation are most common for symptoms, followed by restricted activity and lastly by medical care.

Middle-aged women have a clear preference for using drugs to relieve their symptoms. Lay consultation ranks next, then restricted activity and lastly medical care. Bad physical feelings tend to boost all actions for women, whereas moods have no substantial effect. Middle-aged men have a more complex pattern: They have the highest rate of medical care of any age-sex group; it is especially high on days when they have both low spirits and overall physical malaise. They have no distinct preferences about the other actions; restricted activity, drug use and lay consultation are about equally likely. (One exception: when the day is free of a bad mood or malaise, their rankings are the same as women's.)

For older people of both sexes, mood becomes an important trigger, more so than malaise is. Bad moods especially prompt older women to restrict their activities on symptomatic days. Bad moods prompt older men to talk with family and friends and to seek medical care. Older women's preferences about the four actions have the same ranks as middle-aged women's. Older men's preferences show more variability.

Profiles were also examined from the events-mood perspective (Fig. 9). The patterns within age-sex groups are more complex than those just stated, and the effect of negative events is typically small. They are most likely to spur actions by symptomatic older men and women; least likely to spur them by young people.

\section{How triggers act across days}

Do troubles yesterday (symptoms, malaise, moods, negative events) have a spillover effect, so they

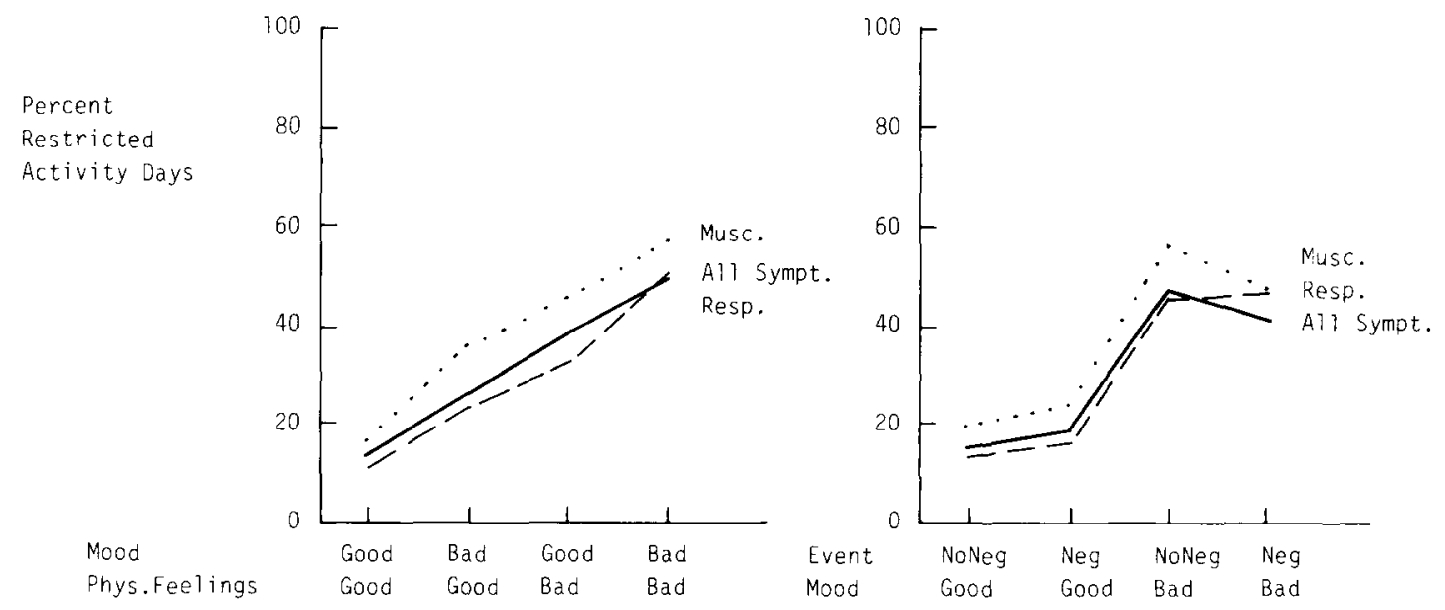

Fig. 7. Triggers of restricted activity on symptomatic days. 


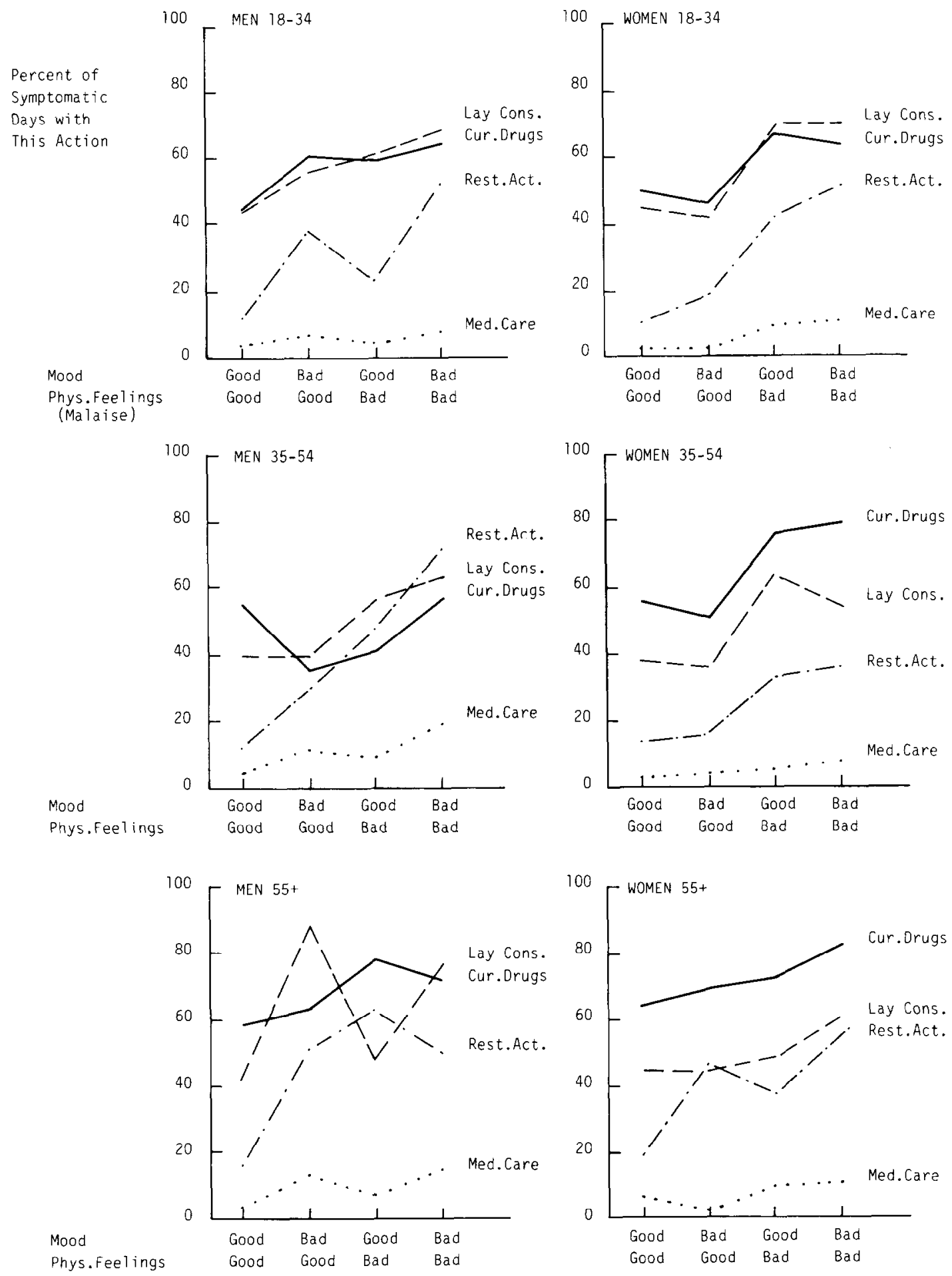

Fig. 8. Health action profiles for age--sex groups: how physical malaise and bad moods trigger four curative behaviors on symptomatic days. 
Percent of

Symptomatic Days with This Action
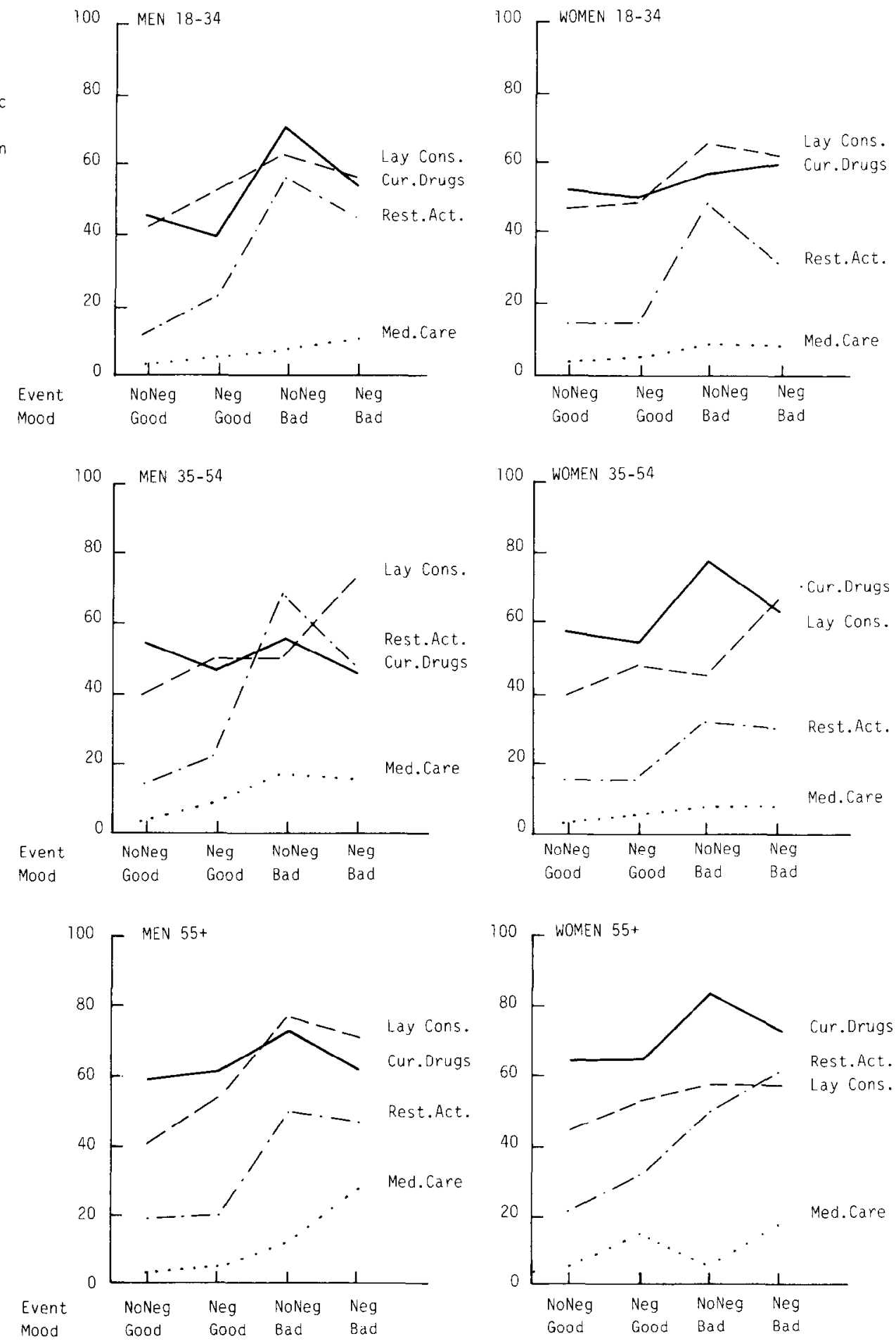

Fig. 9. Health action profiles for age-sex groups: how bad moods and negative events trigger four curative behaviors on symptomatic days. 
influence the likelihood of troubles and health actions today? We begin answering this question with Table 2, which shows today troubles according to the presence or absence of yesterday troubles. In probability terms, these are $P\left[Y_{\text {today }} \mid X_{\text {yesterday }}\right]$ relationships.

Having a trouble yesterday boosts the chances of the same one loday: symptoms are much more likely to occur today if yesterday was symptomatic too $(71.3 \%)$, than if it was symptom-free $(16.8 \%)$. Similarly, bad moods tend to persist $(57.7 \%$ vs $6.2 \%)$ and so do bad physical feelings $(60.2 \%$ vs $5.7 \%$ ). Even negative events tend to recur $(32.9 \%$ vs $10.8 \%$ ). This last result suggests that negative events are not entirely objective or exogenous. Some people may have very nonroutine daily lives, may perceive daily events as negative more than other people do, or may report them more. Furthermore, the likelihood of symptoms today doubles from $33-34 \%$ to $61-68 \%$ if yesterday involved a bad mood or malaise. A negative event yesterday also is linked with symptoms today $(49.4 \%$ if a negative event occurred vs $35.3 \%$ if none occurred). In sum, troubles often occur in episodes of two (or more) days duration. The nexus of mood, symptoms, and malaise which we find within days tend to persist across days as well. Negative events are intertwined with this nexus, and they too 'persist' across days.

Symptoms and other troubles yesterday spur all kinds of health actions today (see bottom panel of Table 2). For example, medical drug use today is more likely if yesterday was symptomatic $(70.5 \%)$ than if it was symptom-free $(44.2 \%)$. Most interesting is how symptoms yesterday influence curative actions today: All of the todays are symptomatic, so we are comparing the likelihood of an action on the second day of an episode with the first day. Symptoms two days in a row motivate people to take curative drugs $(63.3 \%$ vs $46.1 \%$ for the first day), seek medical care $(5.7 \%$ vs $3.4 \%)$, and restrict their activities $(24.4 \%$ vs $21.7 \%$ ).

Table 2 may exaggerate the impact of yesterday triggers because it does not control for today's. Since troubles tend to continue across days, yesterday's solo effect can be revealed only if we first take today's into account. Table 3 controls for today effects; in probability terms it shows $P\left[Y_{\text {today }} \mid X_{\text {today }}, X_{\text {yesterday }}\right]$ relationships. Yesterday's solo effect is seen in the Table by comparing a leftside percent with an adjacent rightside percent. The Table also shows the magnitude of today effects (compare the upper and lower percents within a column) and interaction effects (the difference of margin percents, shown at bottom right in each set). We shall comment on all three kinds of effects.

Yesterday troubles do indeed help trigger mental and physical problems today, and they also boost the chances of all health actions. With few exceptions, the yesterday effects in Table 3 are positive. The principal triggers that act across days are bad moods and bad physical feelings, whereas negative events have smaller, and sometimes reducing, effects.

Medical care is most responsive to yesterday troubles (this is determined by ratios of leftside to rightside percents; not shown). The results suggest that people respond quickly - on the same day-to symptoms by taking drugs they have or can purchase readily, by talking with family and friends, and by cutting down activities, but that they deliberate awhile before taking an action that requires more time, cost and planning.

As expected, today effects are larger than yesterday effects. (This is seen by comparing the differences at the bottom of each set with the differences on the right side.)

Interaction effects show how persistent troubles two days in a row - influence people. They are an extra effect that occurs beyond the yesterday and today effects just discussed. Positive signs mean that repeated troubles exacerbate mental or physical problems or push people strongly to health actions. Such propelling effects are found for three items: the chances that a person feels terrible, takes curative drugs and seeks medical care today are greatly increased if two consecutive days have been troubled by negative events, bad moods, and (for the two actions) malaise. But there are also many negative signs in Table 3, meaning that repeated troubles cause less than expected response (the expected effect being the sum of yesterday and today effects). Such damping effects are found mainly for three items: when two

Table 2. Links between yesterday and today*

\begin{tabular}{|c|c|c|c|c|c|c|c|c|c|}
\hline & \multirow[b]{3}{*}{ Total } & \multicolumn{8}{|c|}{ Yesterday's troubles } \\
\hline & & \multicolumn{2}{|c|}{ Symptoms } & \multicolumn{2}{|c|}{ Negative event } & \multicolumn{2}{|c|}{ Bad mood } & \multicolumn{2}{|c|}{ Physical malaise } \\
\hline & & Yes & No & Yes & No & Yes & No & Yes & No \\
\hline Today's troubles & \multicolumn{9}{|c|}{$(\%$ of all dảysit } \\
\hline Physical symptoms & 37.3 & 71.3 & 16.8 & 49.4 & 35.3 & 61.4 & 33.6 & 67.8 & 32.8 \\
\hline Negative event & 14.0 & 17.6 & 11.9 & 32.9 & 10.8 & 19.1 & 13.0 & 16.9 & 13.4 \\
\hline Bad mood & 13.1 & 21.0 & 8.3 & 18.9 & 11.9 & 57.7 & 6.2 & 52.3 & 7.2 \\
\hline Physical malaise & 12.8 & 22.6 & 6.8 & 17.9 & 11.8 & 51.7 & 6.7 & 60.2 & 5.7 \\
\hline Today's actions & \multicolumn{9}{|c|}{$(\%$ of all days $)$} \\
\hline Medical drug use & \multicolumn{8}{|c|}{ ( $\%$ of symptomatic days) } & 51.3 \\
\hline Curative drug use & 58.2 & 63.3 & 46.1 & 54.3 & 59.3 & 67.9 & 55.8 & 70.8 & 54.5 \\
\hline Medical care & 5.1 & 5.7 & 3.4 & 5.7 & 5.0 & 9.2 & 4.0 & 9.3 & 3.8 \\
\hline Lay consultation & 48.1 & 46.7 & 51.7 & 50.7 & 47.6 & 54.1 & 46.5 & 55.3 & 46.0 \\
\hline Restricted activity & 23.7 & 24.4 & 21.7 & 26.0 & 23.1 & 38.8 & 19.5 & 40.8 & 18.4 \\
\hline
\end{tabular}


Table 3. Yesterday's effects on today, controlling for today's troubles*

\begin{tabular}{|c|c|c|c|c|c|c|c|c|c|c|c|c|c|}
\hline \multirow{3}{*}{$\begin{array}{l}\text { Today } \\
\text { tariables } \\
\text { (dependent) }\end{array}$} & \multirow{3}{*}{$\begin{array}{l}\text { Control: } \\
\text { Score of } \\
\text { control }\end{array}$} & \multicolumn{3}{|c|}{ Symptom today } & \multicolumn{3}{|c|}{ Neg. event today } & \multicolumn{3}{|c|}{ Bad mood today } & \multicolumn{3}{|c|}{ Phys. malaise today } \\
\hline & & \multicolumn{3}{|c|}{ Symptom yesterday } & \multicolumn{3}{|c|}{$\begin{array}{l}\text { Yesterday's tr } \\
\text { Neg. event yesterday }\end{array}$} & \multicolumn{3}{|c|}{$\begin{array}{l}\text { les (predictors) } \\
\text { Bad mood yesterday }\end{array}$} & \multicolumn{3}{|c|}{ Phys. malaise yesterday } \\
\hline & & Yes & No & & Yes & No & & Yes & No & & Yes & No & \\
\hline \multicolumn{14}{|c|}{ (All numbers are percents for today) } \\
\hline $\begin{array}{l}\text { Today's troubles } \\
\text { Symotomatic }\end{array}$ & & & & & & & & & & & & & \\
\hline $\begin{array}{l}\text { Symptomatic } \\
\text { day }\end{array}$ & $\begin{array}{l}\text { Yes } \\
\text { No }\end{array}$ & & & & $\begin{array}{r}59.1 \\
44.6 \\
+14.5\end{array}$ & $\begin{array}{r}52.6 \\
33.1 \\
+19.5\end{array}$ & $\begin{array}{l}+6.5 \\
+11.5 \\
(-5.0)\end{array}$ & $\begin{array}{r}1.8 \\
46.5 \\
+25.3\end{array}$ & $\begin{array}{r}71.3 \\
30.9 \\
+40.4\end{array}$ & $\begin{array}{r}+0.5 \\
+15.6 \\
(-15.1)\end{array}$ & $\begin{array}{r}80.2 \\
48.3 \\
+31.9\end{array}$ & $\begin{array}{r}84.9 \\
29.3 \\
+55.6\end{array}$ & $\begin{array}{r}-4.7 \\
+19.0 \\
(-23.7)\end{array}$ \\
\hline Rad mood & $\begin{array}{l}\text { Yes } \\
\text { No }\end{array}$ & $\bar{\ddagger}$ & & & $\begin{array}{r}31.8 \\
13.0 \\
+18.8 \\
\end{array}$ & $\begin{array}{r}27.9 \\
10.3 \\
+17.6\end{array}$ & $\begin{array}{r}+3.9 \\
+2.7 \\
(+1.2)\end{array}$ & & & & 4 & & \\
\hline $\begin{array}{l}\text { Physical } \\
\text { malase }\end{array}$ & $\begin{array}{l}\text { Yes } \\
\text { No }\end{array}$ & \pm & & & $\begin{array}{r}25.2 \\
14.3 \\
+10.9\end{array}$ & $\begin{array}{r}19.0 \\
11.6 \\
+\quad 7.4\end{array}$ & $\begin{array}{c}+6.2 \\
+2.7 \\
(+3.5)\end{array}$ & $\begin{array}{r}81.1 \\
15.6 \\
+65.5 \\
\end{array}$ & $\begin{array}{r}56.9 \\
3.6 \\
+53.3\end{array}$ & $\begin{array}{c}+24.2 \\
+12.0 \\
(+12.2)\end{array}$ & & & \\
\hline $\begin{array}{l}\text { Today's actions } \$ \\
\text { Medical }\end{array}$ & Yes & 80.5 & 724 & +81 & 646 & 602 & +44 & 74.1 & 688 & +53 & 794 & 751 & +43 \\
\hline drug use & No & $\begin{array}{r}45.8 \\
+34.7 \\
\end{array}$ & $\begin{array}{r}38.4 \\
+34.0\end{array}$ & $\begin{array}{l}+7.4 \\
(+0.7)\end{array}$ & $\begin{array}{r}56.7 \\
+7.9\end{array}$ & $\begin{array}{r}52.3 \\
+7.9\end{array}$ & $\begin{array}{l}+4.4 \\
(+0.0)\end{array}$ & $\begin{array}{r}58.4 \\
+15.7\end{array}$ & $\begin{array}{r}50.6 \\
+18.2\end{array}$ & $\begin{array}{l}+7.8 \\
+(-2.5)\end{array}$ & $\begin{array}{r}61.4 \\
+18.0\end{array}$ & $\begin{array}{r}49.2 \\
+25.9\end{array}$ & $\begin{array}{l}+12.2 \\
(-7.9)\end{array}$ \\
\hline $\begin{array}{l}\text { Curative } \\
\text { drug use }\end{array}$ & $\begin{array}{l}\text { Yes } \\
\text { No }\end{array}$ & 63.3 & 46.1 & +17.2 & $\begin{array}{r}55.1 \\
53.8 \\
+1.3\end{array}$ & $\begin{array}{r}56.0 \\
59.9 \\
-3.9\end{array}$ & $\begin{array}{c}-0.9 \\
-6.1 \\
(+5.2)\end{array}$ & $\begin{array}{r}72.9 \\
57.4 \\
+15.5\end{array}$ & $\begin{array}{r}60.8 \\
55.1 \\
+5.7\end{array}$ & $\begin{array}{c}+12.1 \\
+2.3 \\
(+9.8)\end{array}$ & $\begin{array}{r}75.5 \\
57.6 \\
+17.9\end{array}$ & $\begin{array}{r}62.4 \\
53.3 \\
+9.1\end{array}$ & $\begin{array}{l}+13.1 \\
+4.3 \\
(+8.8)\end{array}$ \\
\hline Medical care & $\begin{array}{l}\text { Yes } \\
\text { No }\end{array}$ & 5.7 & 3.4 & +2.3 & $\begin{array}{r}7.6 \\
4.4 \\
+3.2\end{array}$ & $\begin{array}{r}8.7 \\
4.2 \\
+4.5\end{array}$ & $\begin{array}{l}-1.1 \\
+0.2 \\
(-1.3)\end{array}$ & $\begin{array}{r}10.8 \\
5.5 \\
+5.3\end{array}$ & $\begin{array}{r}6.3 \\
3.6 \\
+2.7\end{array}$ & $\begin{array}{l}+4.5 \\
+1.9 \\
(+2.6)\end{array}$ & $\begin{array}{r}11.2 \\
4.4 \\
+6.8\end{array}$ & $\begin{array}{r}6.1 \\
3.2 \\
+2.9\end{array}$ & $\begin{array}{r}+5.1 \\
+1.2 \\
(+3.9)\end{array}$ \\
\hline Lay consultation & $\begin{array}{l}\text { Yes } \\
\text { No }\end{array}$ & 46.7 & 51.7 & -5.0 & $\begin{array}{r}54.1 \\
48.6 \\
+5.5 \\
\end{array}$ & $\begin{array}{r}55.1 \\
46.1 \\
+9.1 \\
\end{array}$ & $\begin{array}{l}-1.0 \\
+2.5 \\
(-3.6)\end{array}$ & $\begin{array}{r}58.2 \\
25.5 \\
+12.5 \\
\end{array}$ & $\begin{array}{r}61.3 \\
44.1 \\
+17.2 \\
\end{array}$ & $\begin{array}{c}-3.1 \\
+1.4 \\
(-4.7)\end{array}$ & $\begin{array}{r}60.0 \\
42.8 \\
+22.8\end{array}$ & $\begin{array}{r}66.6 \\
42.2 \\
+24.4\end{array}$ & $\begin{array}{c}-6.6 \\
+0.6 \\
(-1.6)\end{array}$ \\
\hline $\begin{array}{l}\text { Restricted } \\
\text { activity }\end{array}$ & $\begin{array}{l}\text { Yes } \\
\text { No }\end{array}$ & 24.4 & 21.7 & +2.7 & $\begin{array}{r}30.5 \\
23.1 \\
17.4\end{array}$ & $\begin{array}{r}26.3 \\
22.5 \\
+3.8\end{array}$ & $\begin{array}{r}+4.2 \\
+0.6 \\
(13.6)\end{array}$ & $\begin{array}{r}47.0 \\
20.7 \\
+26.3\end{array}$ & $\begin{array}{r}44.0 \\
15.6 \\
\\
\end{array} 8.4$ & $\begin{array}{r}+3.0 \\
+5.1 \\
(\quad 2.1)\end{array}$ & \begin{tabular}{|r|}
48.4 \\
20.4 \\
\\
28.0
\end{tabular} & $\begin{array}{r}45.0 \\
13.4 \\
131.5\end{array}$ & $\begin{array}{r}+3.4 \\
+7.0 \\
(\quad 3.6)\end{array}$ \\
\hline
\end{tabular}

*All diary days except the first one for each respondent are used; $N=22,937$ for all days and $N=8,343$ for Symptomatic days. The percents in the first column differ slightly from those in Table 1 because of this.

$\lceil$ For example, the first number in the table (59.1) means "If negative events occurred both yesterday and today, $59.1 \%$ of todays are symptomatic". The number directly below (44.6) means "If yesterday had a negative event but today did not, $44.6 \%$ of todays are symptomatic".

‡Not shown because in this analysis the top variable is treated as dependent on the side variable, not as a predictor for it. For example, symptoms (top variable) are not studied as predictors of bad moods (side variable).

$\S$ For medical drug use, all diary days are used. For the other four actions, only symptomatic days are used.

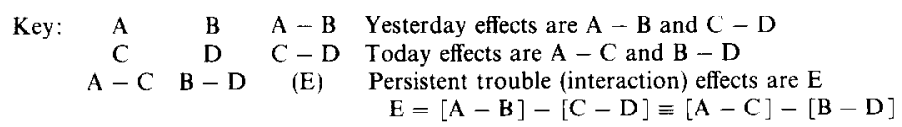

consecutive days are troubled, the chances of symptoms and restricted activity arc less than expected-higher than if just one of the days is troubled, but not much higher. And conversations with family and friends about symptoms actually decrease when troubles persist.

In sum, Table 3 shows that troubles and health actions are triggered more by things happening the same day than by things yesterday. But yesterday does have some spillever impact, so troubles the prior day increase the chances of bad moods, symptoms, malaise, and health actions today. Persistent troubles for two days notably increase the chances of curative drug use and medical care today.

\section{CONCLUSION}

The analyses give ample evidence that bad moods and, to a smaller extent, negative events on a day help

\footnotetext{
*Occasionally a similar effect appears for moods, so that bad moods have more impact on good physical feeling days than they do on bad physical feeling days; for example, see women's medical drug use.

$\dagger$ Negative events also reduce curative drugs on good mood days.
}

spur physical symptoms; and that moods, events and overall physical malaise prod symptomatic people to take curative actions. We now highlight the main results, referring first to the initial hypotheses and then noting other striking results.

Hypotheses 1 and 2 are confirmed for mood, but only partially for negative events. Bad moods are strongly linked with somatic troubles, both physical malaise and symptom experience. They also increase the chances that people will use medical drugs on any day (symptomatic or not) and that symptomatic people will take curative actions (curative drug use, medical care, lay consultation, restricted activity).

Negative events have weaker and also more complex effects. Their impact is usually contingent on the day's mood: when negative events occur on good mood days, they increase the chances of symptoms, medical drug use, medical care, lay consultation and restricted activity*. But on bad mood days, negative events usually reduce the chances of physical malaise, medical drug use, curative drug use, lay consultation and restricted activity $\uparrow$. We conclude, first, that proximal factors (bad moods) take precedence as triggers and distant factors (negative events) operate as triggers in their absence. Second, unpleasant events may some- 
times draw people's attention away from their low spirits and blunt, but not eliminate, the link between emotional and physical distress.

Hypothesis 3 is confirmed. Yesterday troubles (negative event, bad mood, physical malaise, symptoms) do help trigger those same troubles today and also health actions today. Medical care today is especially increased by troubles yesterday. This reflects two time lags - there is some delay before people decide to seek professional help and also a delay between the scheduling and actual contact. (Recall that medical care is counted for making an appointment, getting advice by phone, or visiting a physician. About half of all medical care actions are the first two.)

Triggers have more impact within a day than across days. This is no surprise; for the short-term phenomena we are studying, we expect effects to be quite immediate and to fade rapidly across days.

Hypothesis 4 has some support, but also some surprising results. We begin with the support for propelling effects across days and within days. Persistent troubles across days especially spur medical care and curative drug use. For example, if two days in a row are symptomatic, or if today is symptomatic and both days involved bad moods too, medical care jumps. (See other examples in Table 3.) This means it takes continued troubles for people to seek professional help and secure prescription drugs. (Over two-thirds of the medical drugs taken on symptomatic days are prescription items). Within days, multiple troubles on the day do tend to increase the chances of symptoms and health actions; this comes from the effect of each trouble (additive) and it is visible in the monotonic increases in Figs 1-8. But there is scant evidence of propelling effects, that is, very large jumps in outcomes when two troubles occur*. In sum, propelling effects come mainly from repeated troubles for two days, rather than from multiple troubles within a day.

The surprising results are of damping effects. When two successive days are troubled, we find that lay consultation, restricted activity, and physical symptoms are less frequent than expected. For example, if two days involve bad moods, then restricted activity is less likely today than the expectation, which is based on the sum of yesterday mood and today mood effects. (See other examples in Fig. 3.) A plausible reason for the two health actions is that people begin to focus their efforts on professional care rather than self-care on the second troubled day. Why symptoms are inelastic in face of repeated troubles is perplexing; they do increase when two day both have troubles but not very much. Within days, negative events often show a damping effect, so the combination of an event and bad mood results in better outcomes than having just the bad mood $\dagger$. We have already suggested that people's

*The rare examples are: Malaise plus bad mood on a day propels medical care by middle-aged and older men. A negative event plus bad mood on a day propels lay consultation by middle-aged people.

$\dagger$ There are some examples of damping effects also for the combination of bad mood with malaise; see Figs 3 and 8 . attention may sometimes shift from a prominent trigger (such as bad mood) to a lesser one, thereby blunting the usual impact of the former. Overall, our cxplanations for damping effects involve people's shifting their focus when troubles are heaped across days or within days. We did not predict these in advance, but they do have a plausible interpretation.

There are several other striking findings.

First, the triggers form a simple hierarchy: Bad moods consistently have a stronger triggering effect on physical troubles than negative events do. And for curative health actions, malaise has the strongest effect, followed by bad moods, and lastly by negative events. This ranking of the triggers appears both within days and across them. Assuming that stronger relationships are more direct ones, this matches the causal sequence of the social stress and health model: Disruptive events lead to mental distress, which in turn can induce physical symptoms. Thus, our analysis offers consistent, although rudimentary, support that the social stress and health model operates on a shortterm daily basis.

Second, there are some fascinating clues about age and sex differences in the triggering processes. (1) The social stress and health model may fit women's daily health better than men's. The patterns of trigger effects are simpler and more monotonic for women, but much more variable for men. This suggests that short-term troubles have morc predictable outcomes - for both symptom experience and health actions - for women. (2) Symptomatic women have clearer preferences among health actions than symptomatic men do. Whether the triggers are present or not, women generally turn to curative drugs most readily, then to sympathy and advice from family and friends, then to restricted activity, and lastly to medical care. Men are less consistent, and they often choose drugs, restricted activity, and lay advice about equally. (3) Resilience to daily troubles may decline with age. Triggers tend to operate more vigorously for older people than at other ages, so that they respond more strongly to bad moods and negative events. In fact, negative events are more likely to act as triggers (as originally hypothesized) rather than as dampers at these ages. (4) Bad moods are a more powerful trigger for men than for women, whereas physical malaise affects women more, especially at young and middle ages. The difference is especially obvious in how medical care, restricted activity, and lay consultation are triggered for the sexes. This goes against the grain of popular belief, but we believe it has an explanation. Women may blend their emotional and physical troubles of a day into an overall feeling of malaise; it becomes a summary of how their day felt in gencral. By contrast, men may keep emotional and physical troubles very distinct, so that physical malaise remains an entirely somatic experience. If this notion is true, both sexes respond to emotional distress but in different guises-men principally to moods, and women to malaise. (Some evidence that women's mental and physical troubles permeate each other is in [40].)

Health is a daily and very personal experience, as well as a lifetime, medical one. This analysis shows that there are consistent psychosocial triggers for daily health problems and actions, and that these triggers operate for young, middle-aged, and older men and 
women (with some variations). The chain of life events, mental distress, and physical illness posited for the longrun of life often works for the shortrun of daily negative events, bad moods, and physical problems as well

\section{REFERENCES}

1. Zola I. K. Socio-Medical Inquiries-Recollections, Reftections, and Reconsiderations. Temple University Press, Philadelphia, PA, 1983 (see esp. Chaps 3 and 7 and p. 50).

2. Cohen F. Personality, stress, and the development of physical illness. In Health Psychology - A Handbook (Edited by Stone G. D., Cohen F. and Adler N.), pp. 77-111. Jossey Bass, San Francisco, 1979.

3. Dohrenwend B. S. and Dohrenwend B. P. (Eds) Stressful Life Events and Their Contexts. Prodist (Neale Watson Academic Pub. Inc.), New York, 1981.

4. House J. S. Work Stress and Social Support. Addison-Wesley, Reading, MA, 1981.

5. Kessler R. C. Life events, social support, and mental health. In Deviance and Mental Illness (Edited by Gove W. R.), pp. 247-272. Sage Fublications, Beverly Hills, CA, 1982.

6. Rabkin J. G. and Struening E. L. Life events, stress, and illuess. Science 194, 1013-1020, 1976

7. Wheaton B. Stress, personal coping resources, and psychiatric symptoms: an investigation of interactive models. J. Hlth soc. Behav. 24, 208-229, 1983.

8. Hinkle L. E. Jr, Christenson W. N., Kane F. D., Ostfeld A., Thetford W. N. and Wolff H. G. An investigation of the relation between life experience, personality characteristics, and general susceptibility to illness. Psychosomat. Med. 20, 278-295, 1958.

9. Helsing K. J., Szklo M. and Comstock G. W. Factors associated with mortality after widowhood. Am. J. publ. Hith 71, 802-809, 1981.

10. Haynes S. G. and Eaker E. D. The effect of employment, family, and job stress on coronary heart disease patterns in women. In The Changing Risk of Disease in Women (Edited by Gold E. B.), pp. 37-48. D. C. Heath, Lexington, MA, 1984.

11. Kahn R. L. Work and Health. Wiley, New York, 1981.

12. Kasl S. V. Epidemiological contributions to the study of work stress. In Stress at Work (Edited by Cooper C. L. and Payne R.), pp. 3-48. Wiley, New York, 1978.

13. Husaini B. A., Neff J. A., Newbrough R. and Seymour M The stress-buffering role of social support and personal competence among the rural married. J. Communit. Psychol. 10, 409-426, 1982.

14. Kobasa S. C., Maddi S. R. and Khan S. Hardiness and health: a prospective study. J. Pers. soc. Psychol. 42, $168-177,1982$.

15. Gove W. R. Sex, marital status, and mortality. Am. J. Sociol. 79, 45-67, 1973.

16. Lazarus R. S. The stress and coping paradigm. In Conceptual Models for Psychopathology (Edited by Eisdorfer C., Cohen D. and Kleinman A.), pp. 173-209. Spectrum, New York, 1980.

17. Lazarus R. S., Cohen J. B., Folkman S., Kanner A. and Schaefer C. Psychological stress and adaptation: some unresolved issues. In Selye's Guide to Stress Research (Edited by Sclyc H.), pp. 90-117. Van Nostrand Reinhold, New York, 1980.

18. Verbrugge L. M. Health diaries. Med. Care 18, 73-95, 1980.

19. Roghmann K. J. and Haggerty R. J. The diary as a research instrument in the study of health and illness behavior. Med. Care 10, 1972, 143-163, 1972
20. Roghmann K. J. and Haggerty R. J. Family stress and the use of health services. Int. J. Epid. 1, 279-286, 1972.

21. Roghmann K. J. and Haggerty R. J. Daily stress, illness, and use of health services in young families. Pediat. Res. 7, 520-526, 1973.

22. Holmes T. S. and Holmes T. H. Short-term intrusions into the life style routine. J. Psychosomat. Res. 14, $121-132,1970$.

23. Gortmaker S. L., Eckenrode J. and Gore S. Stress and the utilization of health services: a time series and crosssectional analysis. J. Hlth soc. Behav. 23, 25-38, 1982.

24. Stone A. A. and Neale J. M. Daily life experience and somatic symptoms: a preliminary report. Technical Report prepared for the Office of Naval Research for Contracts N00014-77-C-0693 and N0014-78-C-0625. 1981.

25. Eckenrode J. The impact of chronic and acute stressors on daily reports of mood. J. Pers. soc. Psychol. 46, 907-918, 1984

26. Lewinsohn P. M. and Libet J. Pleasant events, activity schedules, and depression. J. abnorm. Psychol. 79, 291-295, 1972.

27. Rehm L. P. Mood, pleasant events, and unpleasant events: two pilot studies. $J$. consult clin. Psychol. 46, 137-144, 1984.

28. Stone A. A. and Neale J. M. Effects of severe daily events on mood. J. Pers. soc. Psychol. 46, 137-144, 1984.

29. Banks M. H., Beresford S. A. A., Morrell D. C., Waller J. J. and Watkins C. J. Factors influencing demand for primary medical care in women aged 20-44 years: a preliminary report. Int. J. Epid, 4, 189-195, 1975.

30. Lewinsohn P. M. and Talkington J. Studies on the measurement of unpleasant events and relations with depression. Appl. Psychol. Meas. 3, 83-101, 1979.

31. McFarlane A. J., Norman G. R., Streiner D. L. and Roy R. G. The process of social stress: stable, reciprocal, and mediating relationships. J. Hlth soc. Behav. 24, 160-173, 1983.

32. Stone A. A. The association between perceptions of daily experiences and self- and spouse-rated mood. $J$. Res. Pers. 15, 510-522, 1981

33. DeLongis A., Coyne J. C., Dakof G., Folkman S. and Lazarus R. S. Relationship of daily hassles, uplifts, and major life events to health status. Hith Psychol. 1, $119-136,1982$.

34. Kanner A. D., Coyne J. D., Schaefer C. and Lazarus R. S. Comparison of two modes of stress measurement : daily hassles and uplifts versus major life events. J. Behav. Med. 4, 1--39, 1981.

35. Monroe S. M. Major and minor life events as predictors of psychological distress: further issues and findings. $J$. Behav. Med. 6, 189-205, 1983.

36. Verbrugge L. M. Female illness rates and illness behavior: testing hypotheses about sex differences in health. Women Hith 4, 61-79, 1979.

37. Dohrenwend B. S., Krasnoff L., Askenasy A. R. and Dohrenwend B. P. Exemplification of a method for scaling life events: the PERI Life Events Scale. J. Hith soc. Behav. 19, 205-229, 1978.

38. Verbrugge L. M. Health diaries-problems and solutions in study design. In Health Survey Research Methods. (Edited by Connell C. F. and Groves R. M.), pp. 171 192. Research Proceedings Series. DHHS Pub. No. PHS 84-3346. National Center for Health Services Research, Rockville, MD, 1984.

39. Verbrugge L. M. Sex differences in legal drug use. $J$. Soc Iss. 38, 59-76, 1982.

40. Verbrugge L. M. Sex differences in complaints and diagnoses. J. Behav. Med. 3, 327-355, 1980. 


\section{APPENDIX 1}

Daily Health Record

\section{DAILY HEALTH RECORD}

\section{DAY \# 1}

An example Health Record is

included in your folder.

DAY OF THE WEEK

DATE

TIME

1 How did you feel physically today? (Put an " $X$ " in the box which best describes how you felt)

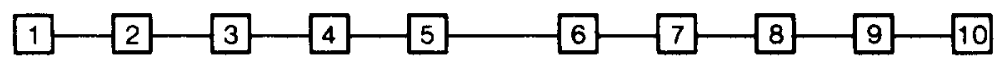
TERRIBLE WONDERFUL 
Did you have any symptoms or discomforts today? (Fill out the chart below from left to right for each symptom or set of symptoms I
ㄴ. Yes
$\sqcap$ 5. No symptoms or
Go to Question 6

SYMPTOM CHART

\begin{tabular}{|c|c|c|c|c|}
\hline $\begin{array}{l}\text { NUMBERS } \\
\text { BELOW } \\
\text { CAN BE USED } \\
\text { IN QS } 3 \text { AND } 4\end{array}$ & $\begin{array}{l}\text { 2a. SYMPTOMS \& } \\
\text { DISCOMFORTS } \\
\text { Write symptoms of the } \\
\text { same health problem in } \\
\text { one box. }\end{array}$ & $\begin{array}{l}2 \mathrm{~b} \text {. CAUSE } \\
\text { lliness, name the } \\
\text { illiness. } \\
\text { Injury, name part } \\
\text { of body hurt and } \\
\text { type of injury. }\end{array}$ & $\begin{array}{l}\text { Not illness or injury. } \\
\text { write what you think } \\
\text { caused the symp- } \\
\text { toms. }\end{array}$ & $\begin{array}{l}\text { 2c. SERIOUSNESS } \\
\text { In your opinion, how } \\
\text { serious was this condition } \\
\text { or set of symptoms today? }\end{array}$ \\
\hline 1 & & & $\begin{array}{l}\vdots \\
\vdots \\
\vdots \\
\vdots \\
\vdots \\
\vdots\end{array}$ & $\begin{array}{l}\square \text { 1. Very Serious } \\
\square \text { 3. Somewhat Serious } \\
\square 5 . \text { Not Very Serious }\end{array}$ \\
\hline 2 & & & $\begin{array}{l}\vdots \\
\vdots \\
\vdots \\
\vdots \\
\vdots \\
\vdots \\
\vdots\end{array}$ & $\begin{array}{l}\square \text { 1. Very Serious } \\
\square \text { 3. Somewhat Serious } \\
\square \text { 5. Not Very Serious }\end{array}$ \\
\hline 3 & & & $\begin{array}{l}\vdots \\
\vdots \\
\vdots \\
\vdots \\
\vdots \\
\vdots \\
\end{array}$ & $\begin{array}{l}\square \text { 1. Very Serious } \\
\square \text { 3. Somewhat Serious } \\
\square 5 . \text { Not Very Serious }\end{array}$ \\
\hline 4 & & & $\begin{array}{l}\vdots \\
\vdots \\
\vdots \\
\vdots \\
\vdots \\
\vdots \\
\end{array}$ & $\begin{array}{l}\square \text { 1. Very Serious } \\
\square \text { 3. Somewhat Serious } \\
\square \text { 5. Not Very Serious }\end{array}$ \\
\hline 5 & & & $\begin{array}{l}1 \\
\vdots \\
\vdots \\
\vdots \\
\vdots \\
\vdots \\
\vdots\end{array}$ & $\begin{array}{l}\square \text { 1. Very Serious } \\
\square \text { 3. Somewhat Serious } \\
\square \text { 5. Not Very Serious }\end{array}$ \\
\hline
\end{tabular}


Because of today's symptoms, did you cut down on the things you usually do?
1. Yes
$\square$ 5. No
Go to Question 4

Answer 3 a through $3 \mathrm{e}$
3a. Did you stay in bed?
$\square$ No
$\square$ Yes
3b. Did you cut down on household chores or errands?
$\square$ No
$\square$ Yes
3c. Did you miss work?
$\square$ No
$\square$ Yes
3d. Did you miss school?
$\square$ No
Yes

3e. Did you cut down on other activities you planned to do (sports. clubs, church, etc.)?

$\square$ No

$\square$ Yes
For which symptom, illness, or injury? (Write in number from symptom chart, question 2)

Did you seek medical or dental help about today's symptoms?
—1. Yes
$\square$ 5. No
Go to Question 5

\section{Answer 4a through $4 \mathrm{e}$}

4a. Did you make an appointment with a doctor or dentist? $\square$ No

$\square$ Yes

4b. Did you telephone a clinic, doctor's office or dentist's office and get advice?

$\square$ No

$\square$ Yes

4c. Did you visit a clinic, doctor's or dentist's office or an emergency room?
$\square$ No
$\square$ Yes

4d. Did you get admitted to a hospital?
$\square$ No
$\sqcup$ Yes

4e. Was there anything else you did? (IF YES: What was that?)

$\square$ No

$\square$ Yes
For which symptom, illness, or injury? (Write in number from symptom chart, question 2) 
Did you talk with anyone else today - such as relatives, neighbors, friends - about your symptoms?
1. Yes
$\square$ 5. No
Go to Question 6

5a. Who did you talk with? (Check all boxes that apply.)

$\square$ A. Your husband/wife

$\sqcap$ B. Other member of your household

$\square$ C. Relative not living with you

$\square$ D. Neighbor, coworker, friend (who is not a relative or household member)

$\square$ E. Other person (druggist. minister, priest, etc.) Who did you speak with?

Did you visit or telephone a clinic, doctor or dentist's oftice, or hospital today for any reason besides symptoms you might have had today?
$\square$ 1. Yes
$\square$ 5. No
Go to Question 7

6a. For what reasons? 
7 Did you take any pills, medicine, or treatments for your health today - to treat a symptom, prevent illness, or to become more healthy in general? (F/ll out the chart below from lett to right)

$\square 1$. Yes
П. No pills medicine or treatment taken at all
Go to

Question 8

\begin{tabular}{|c|c|c|c|c|}
\hline & $\begin{array}{l}\text { 7a. PILLS, MEDICINE, TREAT- } \\
\text { MENTS } \\
\text { If pills or medicine, write the } \\
\text { brand name from the label and } \\
\text { the type of drug Use one bux for } \\
\text { each pill, medicine or treatment. }\end{array}$ & $\begin{array}{l}\text { 7b. REA } \\
\text { PILL } \\
\text { MEI } \\
\text { lChe } \\
\text { A. To tre } \\
\text { you to } \\
\text { B. For ot } \\
\text { bothe } \\
\text { C. To p } \\
\text { becon } \\
\text { gener } \\
\text { D. Other }\end{array}$ & $\begin{array}{l}\text { ASONS FOR TAKING } \\
\text { S. MEDICINE. TREAT- } \\
\text { NTS } \\
\text { eck all boxes that apply.) } \\
\text { at symptoms bothering } \\
\text { day } \\
\text { her health problem not } \\
\text { ring you today } \\
\text { revent illness or to } \\
\text { ne more healthy in } \\
\text { al } \\
\text { reasons }\end{array}$ & $\begin{array}{l}\text { 7c. SYMPTOM OR CONDITION } \\
\text { What was the symptom, health } \\
\text { problem, or other reason for tak- } \\
\text { ing pills, medicine, or treatment? }\end{array}$ \\
\hline 1 & & $\square \mathrm{A}$ & $\begin{array}{l}\square \text { B } \square \mathrm{C} \quad \square \mathrm{D} \\
\text { Go to 7c }\end{array}$ & \\
\hline 2 & & $\square \mathrm{A}$ & $\begin{array}{l}\square \mathrm{B} \quad \square \mathrm{C} \quad \square \mathrm{D} \\
\text { Go to } 7 \mathrm{C}\end{array}$ & \\
\hline 3 & & $\square \mathrm{A}$ & $\begin{array}{l}\square \mathrm{B} \quad \square \mathrm{C} \quad \square \mathrm{D} \\
\text { Go to } / \mathrm{C} \Rightarrow\end{array}$ & \\
\hline 4 & & $\square \mathrm{A}$ & $\begin{array}{l}\sqcup \mathrm{B} \quad \sqcup \mathrm{C} \sqcup \mathrm{D} \\
\text { Go to } 7 \mathrm{C} \boldsymbol{M}\end{array}$ & \\
\hline 5 & & $\square \mathrm{A}$ & $\begin{array}{l}\square \mathrm{B} \quad \square \mathrm{C} \quad \square \mathrm{D} \\
\text { Go to } 7 \mathrm{C} \Rightarrow\end{array}$ & \\
\hline
\end{tabular}


How were your spirits today? (Put an " $X$ " in the box which best describes how you felt today)

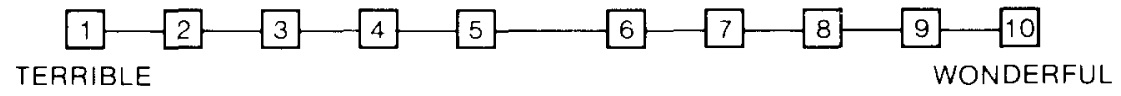

Did anything happen - for better or worse - to make today different than usual?

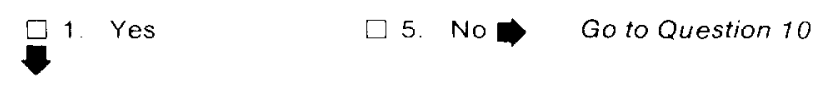

9a. What happened? (Check all boxes that apply.)

[.] A. Birthday, holiday, or special social event

[ B. Trip or vacation

๑. Emergency

$\square$ D. Trouble with family or friends

$\square$ E. Something extra nice with family or friends

$\square$ F. A lot of extra work

$\square$ G. Guests

$\square$ H. Other: What happened?

10 Any other comments:

\section{REMINDER:}

IF you had any symptoms today

Be sure you answered Questions $1,2,3,4,5,6,7,8$, and 9 .

IF you had no symptoms today:

Be sure you answered Questions 1, 2, 6, 7, 8, and 9 . 